\title{
4. BOND BETWEEN CONCRETE AND STEEL
}

The bond behaviour under alternating loading is analysed following a short description of the behaviour under monotonically increasing slip and unidirectional cyclic loading, respectively. Various proposals for modeling are discussed and evaluated.

\subsection{Introduction}

The behaviour of reinforced concrete structural elements, subjected to large alternate actions, is highly dependent on the interaction between steel and concrete. In earthquake resistant design of structures, economical requirements usually lead to the need for large seismic energy input absorption and dissipation through large but controllable inelastic deformations. The structural and non structural damage incurred from an earthquake should not lead to collapse of the structure or to the endangerment of human life. Therefore the sources of potential structural brittle failure must be eliminated and degradation of stiffness and strength under repeated loadings must be minimized or delayed long enough to allow sufficient energy to dissipate through stable histeratic behaviour.

In reinforced concrete, one of the sources of brittle failure is the sudden loss of bond between reinforcing bars and concrete, which has been the cause of severe local damage to, and even collapse of, many structures during strong earthquakes. Even if no anchorage failures occur, the histeratic behaviour of reinforced concrete structures, subjected to alternate actions, is highly dependent on the interaction between steel and concrete.

Cyclic loadings are generally divided into two categories. The first cathegory is the so-called "low-cycle" loading, or a load history containing few cycles (less than 100 ) but having very large bond stress ranges. Low-cycle loadings commonly arise in seismic and high wind loadings. The second category is the socalled "high-cycle" or fatigue loading, which is a load history containig many cycles (typically thousands or 
millions), but at a low bond stress range. Bridge members, offshore structures, and members supporting vibrating machinery are often subjected to "high-cycle" or fatigue loading. High cycle loadings are considered a problem at service load levels, while low cycle loading produce problems at the ultimate limit state.

The bond behaviour under cyclic loading can further be subdivided according to the type of stress applied. The first is repeated or unidirectional loading, which implies that the bar stress does not change sense (tension to compression) during a load cycle, the usual situation for fatigue loading. The second is reversed cycle loading, where the bar is subjected alternatively to tension and compression. Stress reversals are the typical cases for seismic loading.

In this chapter, the behaviour of bond under low cycle loading is described.

\subsection{Bond behaviour under monotonically increasing slip}

Bond behaviour is a combination adhesion, bearing of lugs and friction. Adhesion is related to the shear strength of the steelconcrete interface and is the result primarily of chemical bonding. Bearing forces perpendicular to the lug faces arise as the bar is loaded and tries to slide. In this phase microcracking [1] and micro-crushing [2] of concrete in front of lugs are produced. Friction is produced by bearing force on the interactional surface and by shearing off the concrete between the lugs on the cylindrical concrete surface at the tip of lugs.

As both experimentally and theoretically was prooved [3], bond stress is a basical function of slip where latter indicates the relative displacement between the steel and concrete crosssection. The relationship of them is called bond stress-slip relationship.

Besides the slip, concrete strength, concrete cover, bar size, rib pattern of bar, confining effects, casting position with respect to loading, distance to cracks, temperature, surface coating of bar, type, rate or duration of loading have influence on bond behaviour. Extensive guidance on the influencing factors is available in Ref.4.

Under monotonic loading two types of bond failures are typical. The first is a direct pullout of the bar, which occurs when ample confinement is provided to the bar. The concrete immediately surrounding the bar fails due to the shearing of the concrete between the lugs. Pullout failures depend primarily on the concrete strength 
and the pattern and geometry of the deformations. The second type of failure is a splitting of the concrete cover when the cover or confinement is insufficient to obtain a pullout failure. In this case the failure is due primarily to the tensile radial stresses caused by the lug bearing forces. Splitting propagates to the edges of the member resulting in loss of cover and bond. The orientation of the splitting cracks depends on the number of bars and their configuration within the member.

Failure modes under low-cycle loading are very similar to those under monotonic loading. Under high-cycle loading similar failure modes can occur, but fatique failure of both reinforcing bar and concrete is to be considered.

Bond stress versus slip curves for a bar loaded monotonically and failing by pullout are shown in Fig.1 [5]. The relationship shown is dependent on the degree of confinement as well as the status of stress in the concrete surrounding the bar (tension or compression).

For analytical applications, several linear and nonlinear approximations of the bond stress-slip relationship are available. The one which CEB MC 90 [6] incorporated is based on the proposal by Eligehausen, Popov and Bertero [5]. It consists of an initial nonlinear relationship $\tau=\tau_{1}\left(s / s_{1}\right)^{\alpha}$ valid for $s \leq s_{1}$, followed by a plateau $\tau=\tau_{1} s_{1} \leq s \leq s_{2}$ (Fig.2). For $s \geq s_{2}, \tau$ decreases linearly to the value of the ultimate frictional bond resistance $\tau_{3}$ at a slip value of $s_{3}$. This value $s_{3}$ is assumed to be equal to the clear distance between the lugs of the deformed bars. The same bond stress-slip relationship is assumed regardless of whether the bar is pulled or pushed. Different values of the $s_{1}, s_{2}, s_{3}, \alpha, \tau_{\max }$ parameters are proposed for unconfined concrete regions (failing by splitting of concrete cover) and for confined concrete regions (failing by pull-out) (see in Fig.2).

Some other proposals may differ in the mathematical form of the relationship and the values of parameters, respectively.

\subsection{Bond behaviour under unidirectional cyclic loading}

Cyclic loading produces a progressive deterioration of bond. The deterioration can be observed as a slip increment [7], [8], [9]. This process can lead to failure at a cyclic stress level lower than the ultimate stress under monotonic loading. 


\section{$\tau\left[\mathrm{N} / \mathrm{mm}^{2}\right]$}
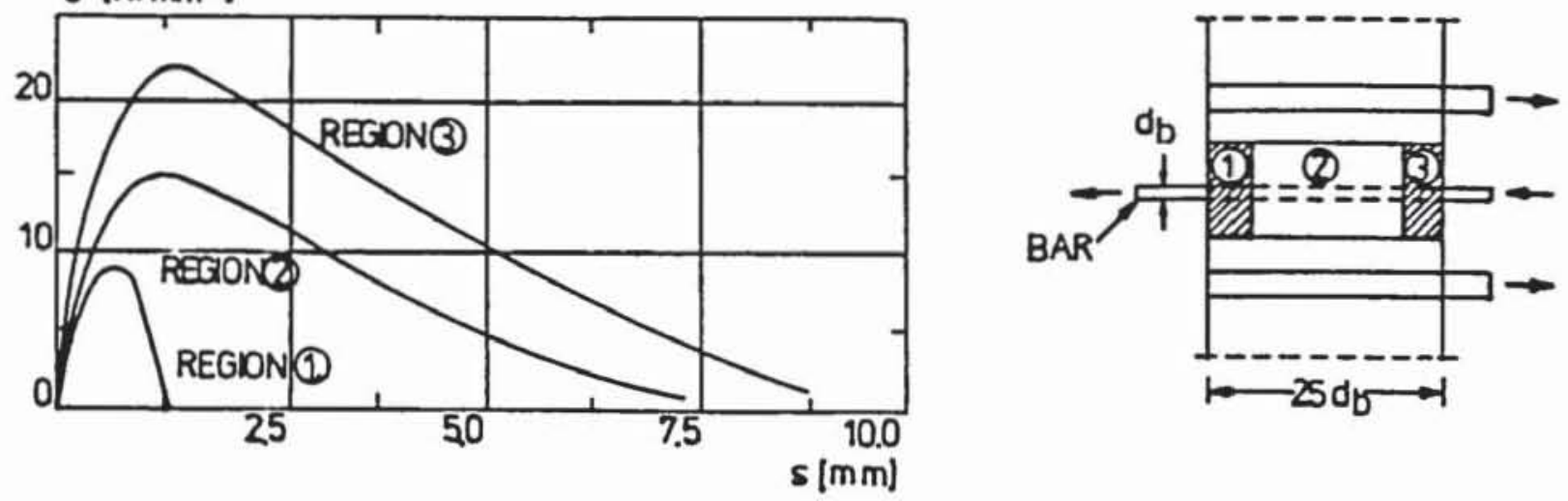

REGION (1) UNCONFINED CONCRETE W TENSION

REGION (2) CONFINED CONCRETE

REGDN (3) UNCONFINED CONCRETE N COMPRESSON

Fig.1 Monotonic bond stress vs. slip curves, Eligehausen, Popov and Bertero [5]

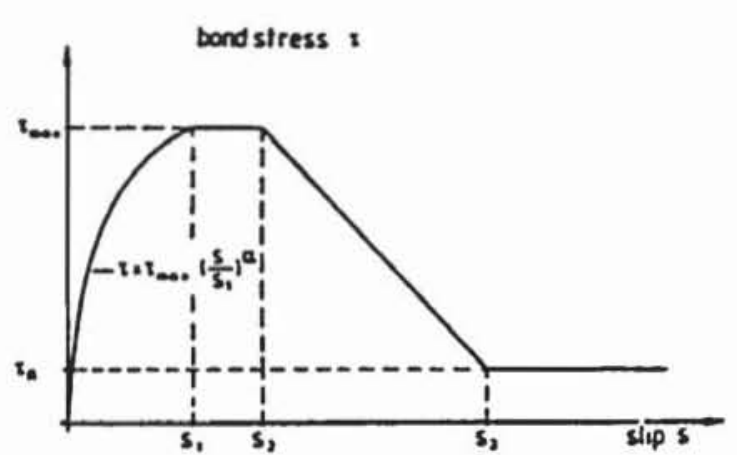

Fig.2 Analytical bond stressslip relationship for monotonic loading, CEB Bull No. 195 [6]

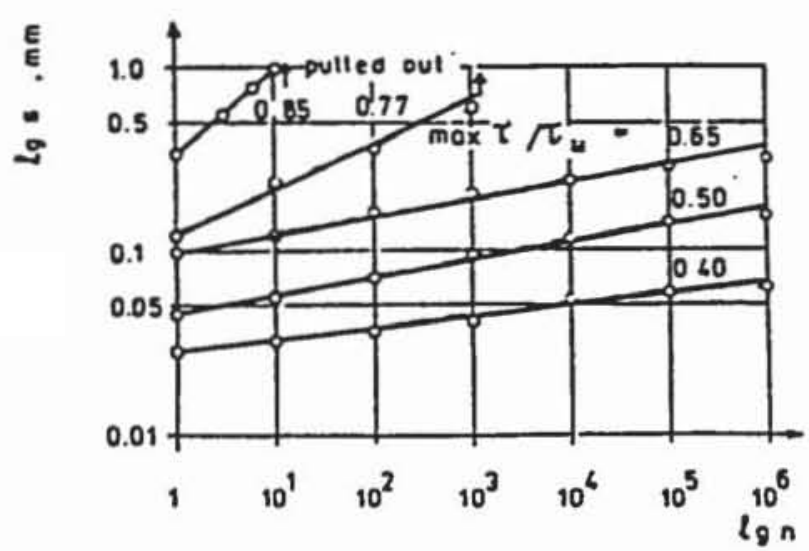

Burameters for defining the bend stresseslip-relationshis

\begin{tabular}{|c|c|c|c|c|}
\hline & 2 & 3 & 4 & 5 \\
\hline Value & \multicolumn{2}{|c|}{ Uncoofined concreac" } & \multicolumn{2}{|c|}{ Coofined coocrete"* } \\
\hline & \multicolumn{2}{|c|}{ Bond conditions } & \multicolumn{2}{|c|}{ Bond conditions } \\
\hline & Good & $\begin{array}{l}\text { All ouher } \\
\text { cases }\end{array}$ & Good & $\begin{array}{l}\text { All ocher } \\
\text { cases }\end{array}$ \\
\hline$s_{1}$ & $0.6 \mathrm{~mm}$ & $0.6 \mathrm{~mm}$ & \multicolumn{2}{|c|}{$1.0 \mathrm{~mm}$} \\
\hline$s_{2}$ & $0.6 \mathrm{~mm}$ & $0.6 \mathrm{~mm}$ & \multicolumn{2}{|c|}{$3.0 \mathrm{~mm}$} \\
\hline$s_{2}$ & $1.0 \mathrm{~mm}$ & $2.5 \mathrm{~mm}$ & \multicolumn{2}{|c|}{ clers rib spocing } \\
\hline $\mathbf{a}$ & \multicolumn{2}{|c|}{0.4} & \multicolumn{2}{|c|}{0.4} \\
\hline$=$ & $20 \sqrt{10}$ & $10 \sqrt{5}$ & $25 \sqrt{1}$ & $1.25 \sqrt{1.0}$ \\
\hline y & \multicolumn{2}{|c|}{$0.15=$} & \multicolumn{2}{|c|}{0.402} \\
\hline
\end{tabular}

- Failure by splitiing of the concreac

- Failure by shearing of the concreas between the ribs

Fig.3 Unloaded-end vs. number of load cycles diagrams under cyclic loading, $\phi 14, I_{\mathrm{b}}=3 \phi, f_{\mathrm{c}}=23 \mathrm{MPa}$ Rehm and Eligehausen [9] 


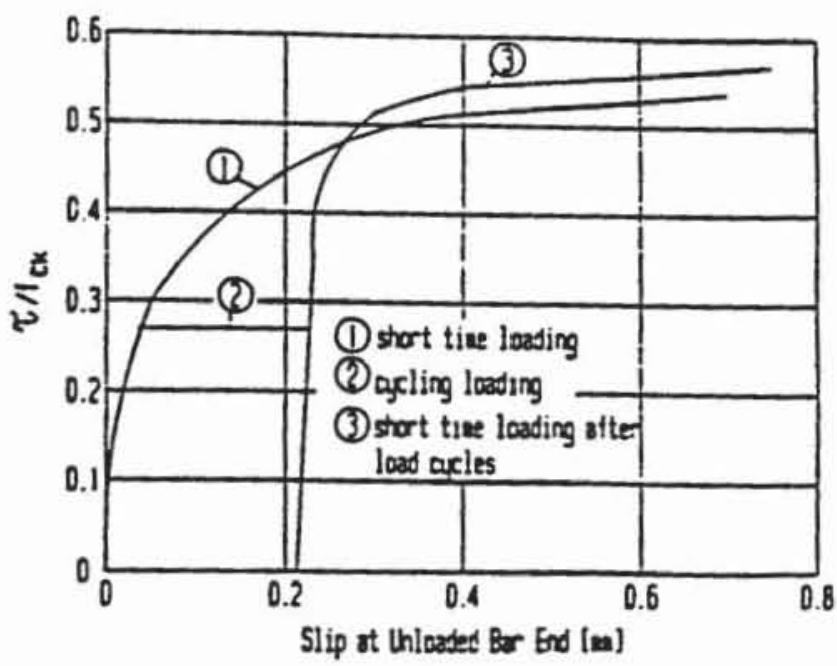

Fig.4 Effect of cyclic load on static bond strength, Rehm and Eligehausen [9]

a)

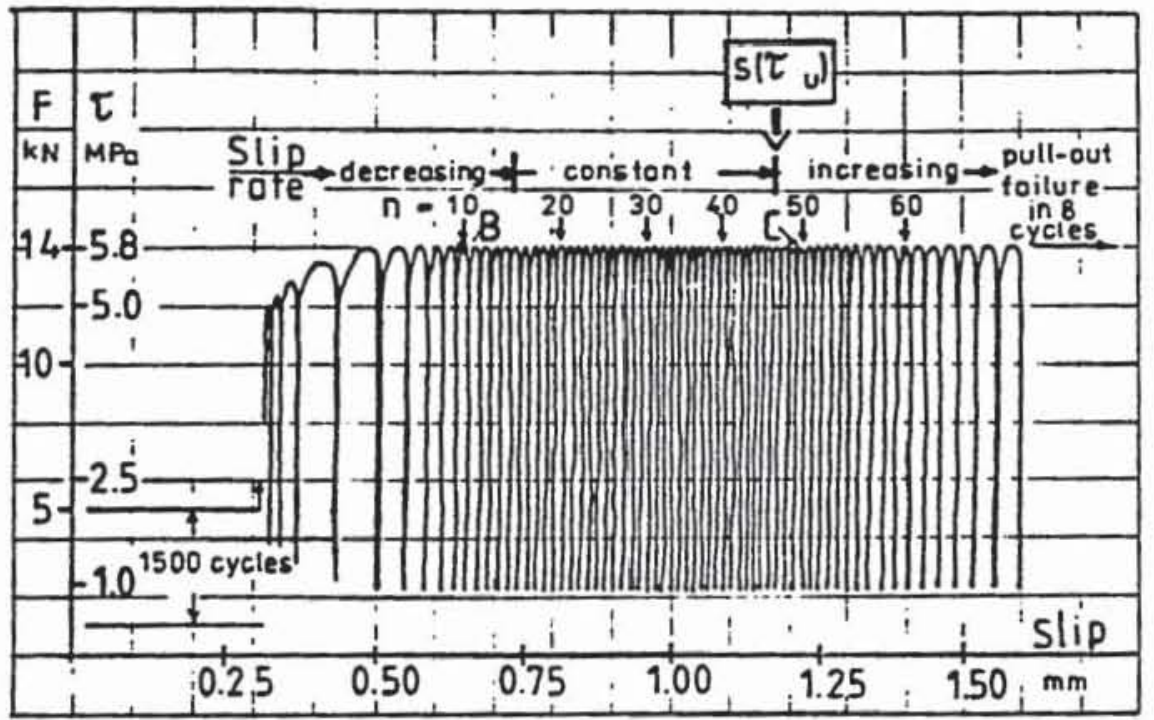

$$
\text { Ff }
$$
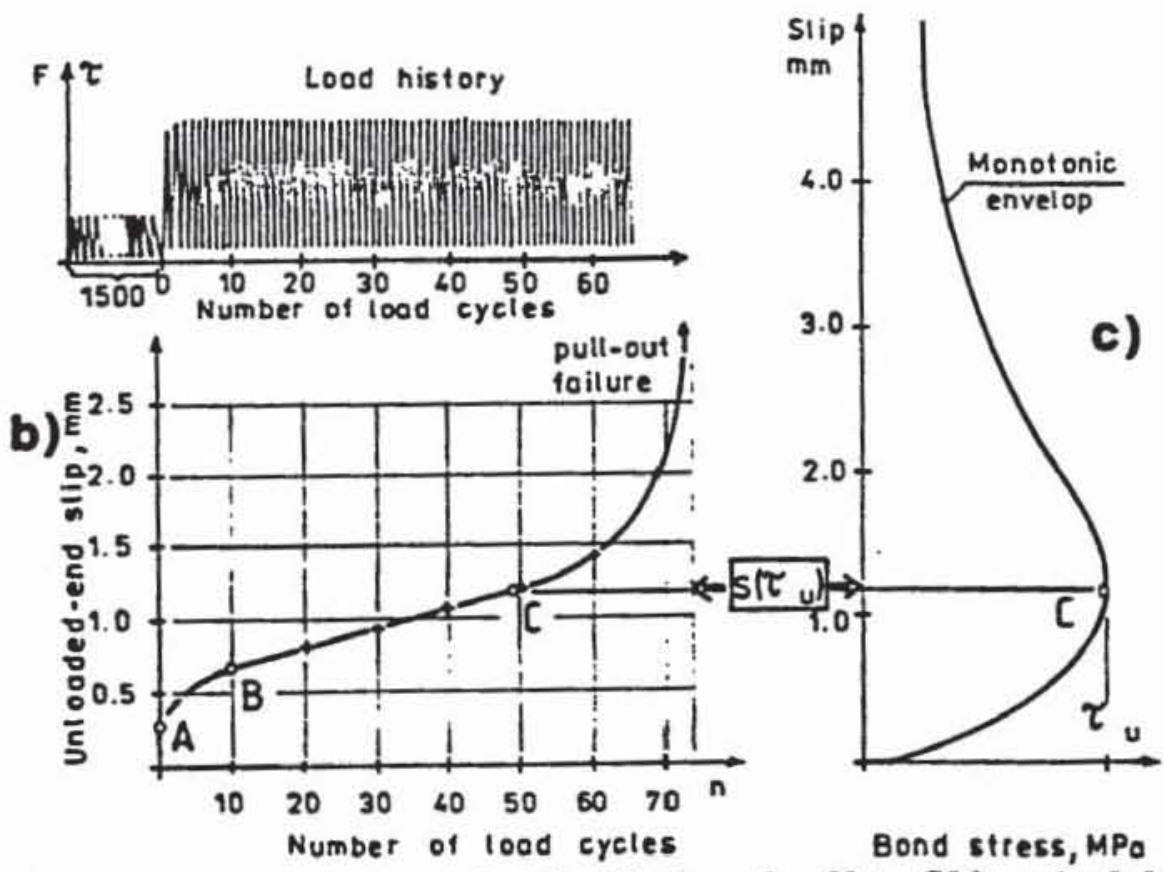

Fig.5 Bond fatigue process, test result: $\phi 8$ def. bar, $I_{\mathrm{b}}=12 \phi$, C16, unloaded and diagram Balazs [11] 


\subsubsection{Behaviour}

According to the pull-out test results of Rehm and Eligehausen [9] with constant amplitude cyclic loading, if no fatigue failure of bond, occurs the slip versus number of load cycles relationship in double logarithmic scale is approximately linear (Fig.3).

Rehm and Eligehausen [9] also concluded that if a fatigue failure of bond does not occur, then previous load cycles do not negatively affect the bond stress-slip behaviour near ultimate load compared with the monotonic loading behaviour (Fig.4).

Otherwise the comparison of test results with cyclic and sustained loading show [9] that cyclic loading can be considered as a time accelerator compared with a sustained load.

Based on pull-out test results with cyclic load Balázs [11], [12] distinguished three different phases of the bond fatigue process (Fig.5). During the beginning of load cycles (1st phase) the slip rate is decreasing then (2nd phase) keeps constant which is finally followed by a rapid increase (3rd phase) producing pullout failure

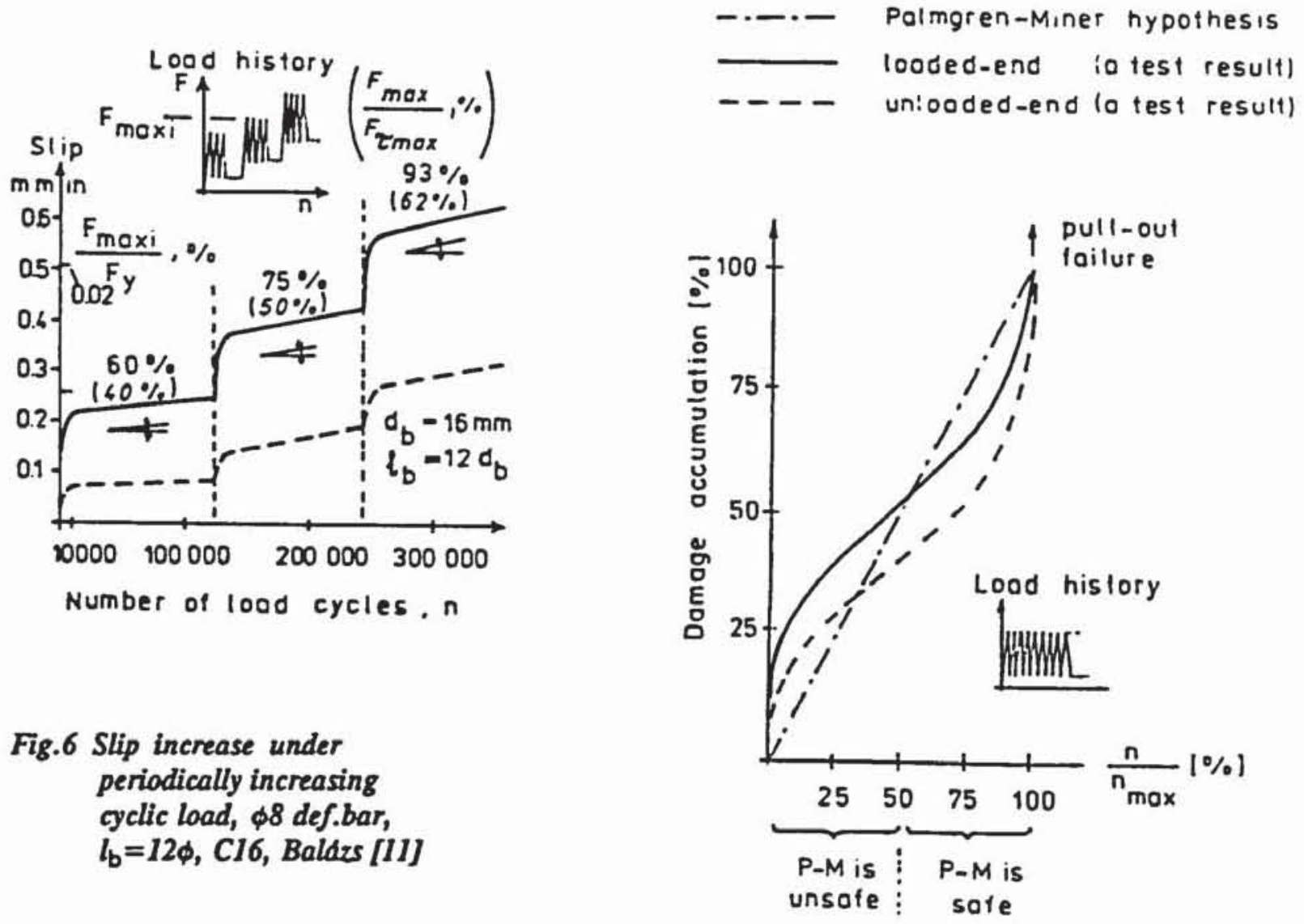

Fig.7 Bond damage accumulation with respect to the Palmgren-Miner hypothesis, test result: $\phi 8$ def.bat, $l_{\mathrm{b}}=12 \phi$, C16, Balázs [11] 
(Fig.5.a). Presenting the slip versus number of load cycles relationship in normal scale it contains concave, linear and convex portions (Fig.5.b). The intermediate linear portion closes by $s\left(\tau_{\omega}\right)$, being the slip at monotonic bond strength which, at the same time, is the beginning of the failure branch. Therefore, $s\left(\tau_{w}\right)$ is proposed [11] as a safe fatigue failure criterion.

Load history has a significant effect on slip. For instance [11] a periodical increase of the maximum value of cyclic force produces a higher slip rate of the intermediate linear portion (Fig.6).

The accumulation of bond damage is supposed to be caused by the progressive growth of micro-cracks and concrete crushing in front of the ribs. Their effect is observed by increasing slips. Thus, increase of slip can demonstrate the damage accumulation of bond.

Test results by Balázs [11] show three different phases of slip versus number of load cycles behaviour for constant amplitude cyclic bond tests and not a linear relationship as the Palmgren-Miner hypothesis supposes (Fig.7). During the first phase and third phase the fatigue damage proceeds more quickly than predicted by the hypothesis. In the intermediate linear stage the damage is less quick [11].

\subsubsection{Model by Fehling}

A physically oriented bond model was developed by Fehling [29] in order to model the bond-behaviour under cyclic loading and the dissipation of energy due to bond hysteresis. The model consists of a strut-and-tie-structure representing the conrete around the reinforcing bar taking into account:

- local plasticity of conrete at the lugs of rebars,

- internal cracks (cone shaped),

- splitting cracks (longitudinal cracks),

- deformation of rebars in transverse and longitudinal direction,

- friction effects between concrete and steel,

- creep effects considering general load histories,

- damage due to cyclic loading

For the physical modeling of bond the stress-strain-relation of concrete under 
triaxial stress conditions and for high values of strain is required. As a result of tests with high local compressive bearing stresses, Lieberum [30] found a relationship between the porosity of the cement matrix and the amount of possible plastic strains (Fig.8.a).

The unloading stiffness is assumed to be equal to $E_{c 3}$. A simple assumption of the distribution of stresses (Fig.8.c) in the range where plastic strains occur (Fig.8.b) in combination with the stressstrain-law mentioned above, enables the calculation of plastic deformation of concrete contributing to the total slip using a strutand-tie-model (Fig.8.d).

For modeling the unloading and reloading branches, the plastic zone near a lug of the rebar may be described by the system consisting of springs and friction elements as shown in Fig.8.e. Friction is adopted as being composed of a constant term (selfinduced radial stresses $F_{v}$ and cohesion) and a term due to radial stresses in the steel-concreteinterface due to bond stresses (radial component of force $\mathrm{D}$ in Fig.8.e).

The strut-and-tie-model enables to consider the influence of steel strains in logitudinal as well as in transverse direction. The longitudinal tensile strains in the rebar are associated with transverse contraction contributing to the total amount of slip. Furthermore, the local steel strain in direction of the rebars is interesting with respect to the width of internal cracks. The inclination of internal cracks is considered in the strut and tie model leading to differences in modeled frictional behaviour near transverse cracks and in more distant regions.

Transverse conrete stresses influencing the frictional behaviour as well as the capacity of the concrete cover (with respect to longitudinal cracking) can easily be included into the model. Assuming fully plastic distribution of circumferential tensile concrete stresses around the rebar the limit of bond stress due to longitudinal cracking is checked for each load step.

In order to model the damage due to cyclic loading the hypothesis is made, that damage is caused by abrasion and transport of particles into the open internal cracks. Thus, the width of internal cracks as well as the sum of the absolute values of slip increments form the basic parameters of the damage model. In addition to the damage associated with slip reversals the effect of bond-creep, which also contributes to bond softening, is modeled using the bond-creep-law proposed by Rohling and Rostásy [31]. The damage model is desribed in more detail in [29].

The results obtained with this simple model were sufficient for the loading and 


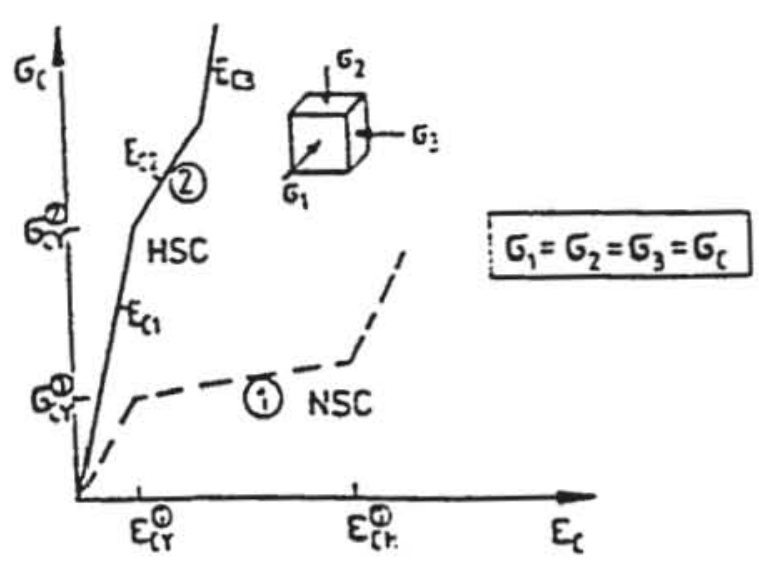

(a) Stress-strain curves of concrete of different strength under 3-axial hydrostatic compression

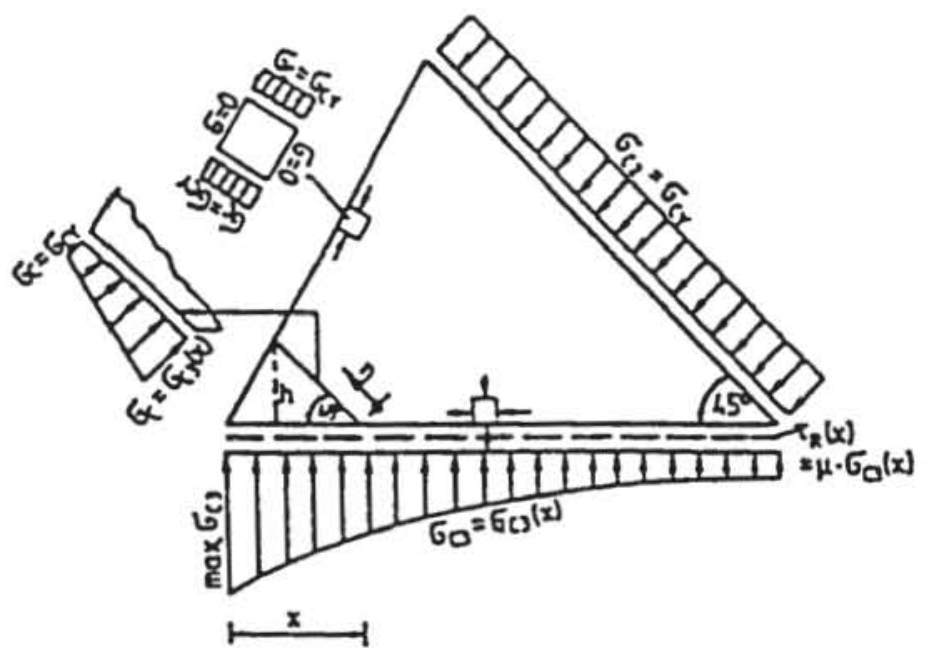

(c) Assumed stress distribution near lug of rebar

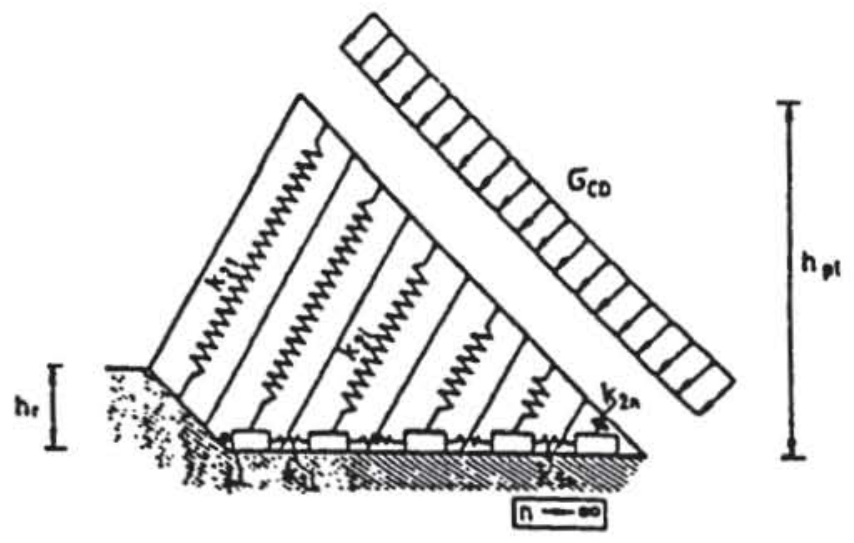

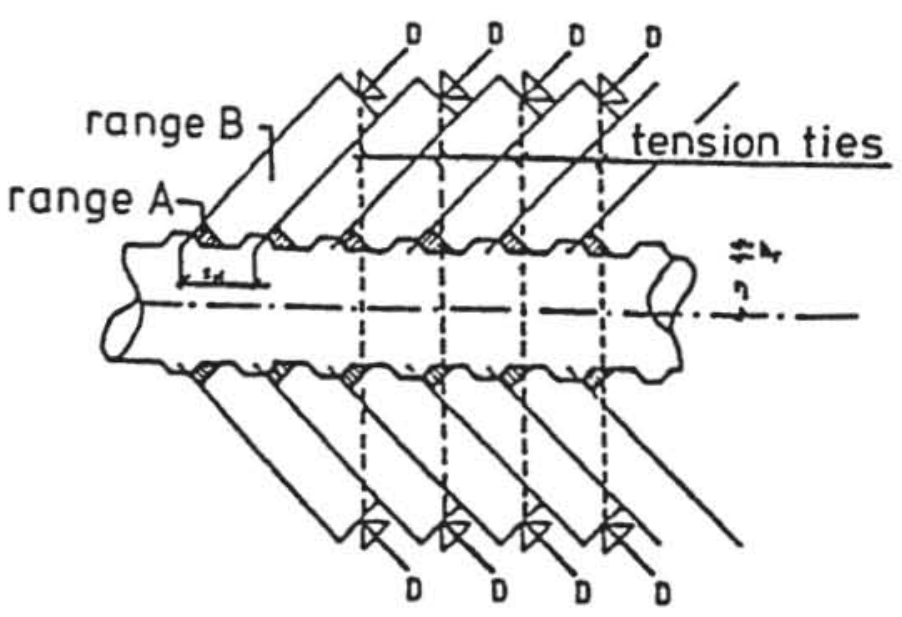

(b) Modeling of local bond behaviour

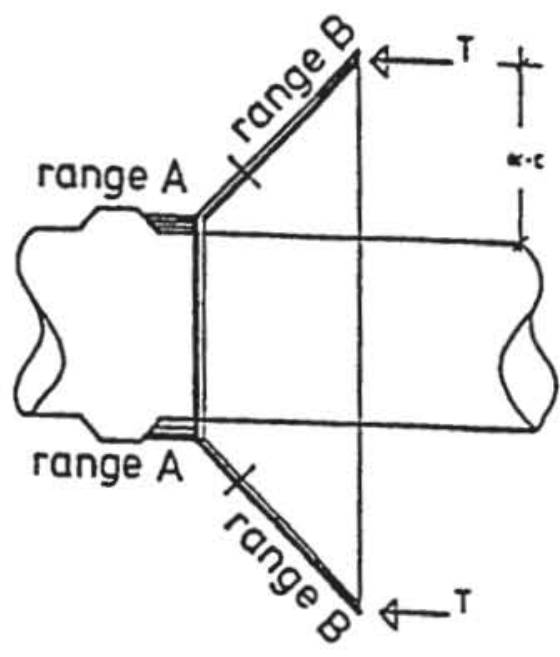

(d) Strut-and-tie model

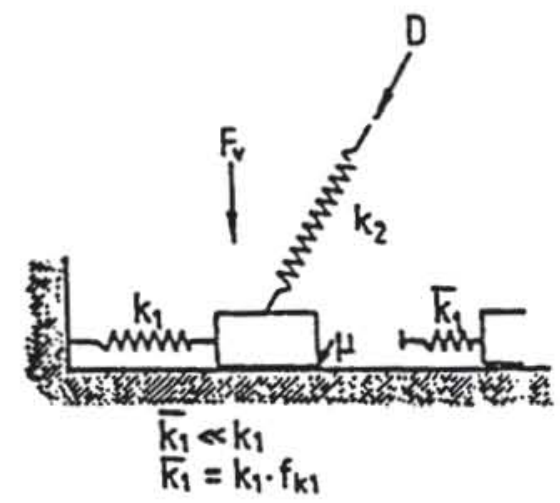

(e) Un- and reloading in the platic zone (model and simplif.) 
unloading branches but not for the reloading branch. The test results showed a more pronounced increase of bond stress when the actual slip during reloading aproaches the maximum slip reached before. This may be explained by the necessity of compacting a volume of particles in the plastic zone, which have been loosened up during unloading and leads to a nonlinear force deformation curve which can be incorporated into the model. Also, aggreate interlock effects in internal cracks may contribute to the observed effect.

The comparison of the computed local bond behaviour according to the test results showed the significant influence of distance to the crack on frictional bond stresses, which could not be fully explained by different angles of mean stresses and internal cracks. It is assumed, that aggregate interlock in internal cracks plays an important role for the frictional bond stresses. Thus, the local value of frictional bond stress, originally assumed to be constant, is modified depending on the distance ot the next transverse crack.

Besides some factors for the damage model as well as the frictional parameters, which all should be taken as constant for all types of concrete under investigation, the proposed analytical bond model only requires the input of geometric variables describing the rebars and their lugs as well as strength and strain values for the concrete. It could be shown, that the model is able to predict the bond behaviour for different concrete strengths and bar diameters satisfactorily. The computational effort to follow the local strains within the strut-and tie model is limited and - with respect to the high speed of modern personal computers or mainframes - does not play an important role.

A comparison of test results and the results of the theoretical model is presented in Fig.9.a and 9.b.

Although the model in the present formulation is oriented towards repeated (or unidirectional) loading it is possible to include the mechanisms required for modeling of reversed loading.

\subsection{Bond behaviour under alternating loading}

In the case of reversed cyclic loading the type of loading (load or slip controlled), and the rate of loading (frequency) are important parameters for bond strength [14], [15]. Seismic loading, the most common case of reversed cyclic 
(a) Test result

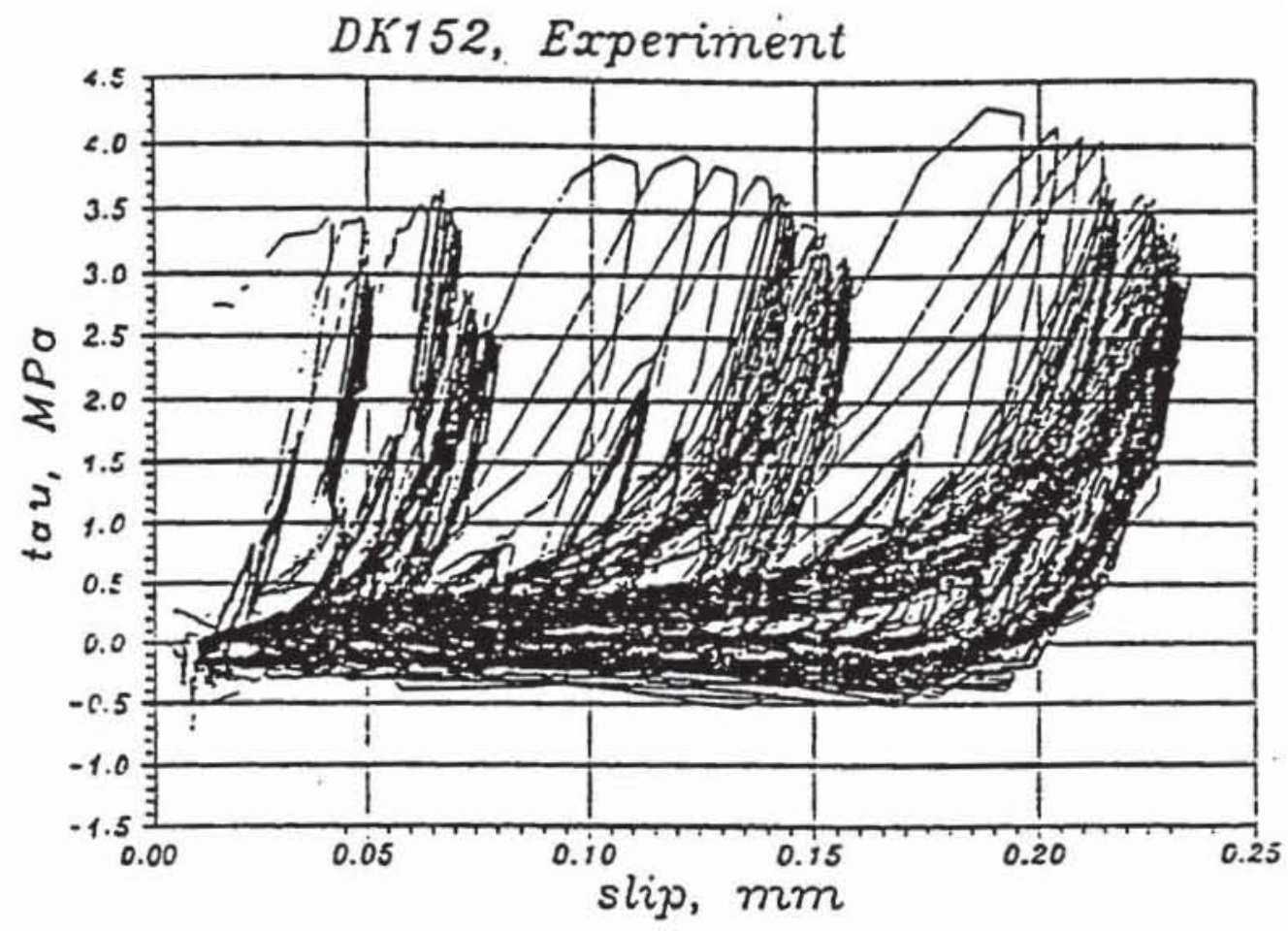

(b) Result of calculation using the model indicated in Fig. 8

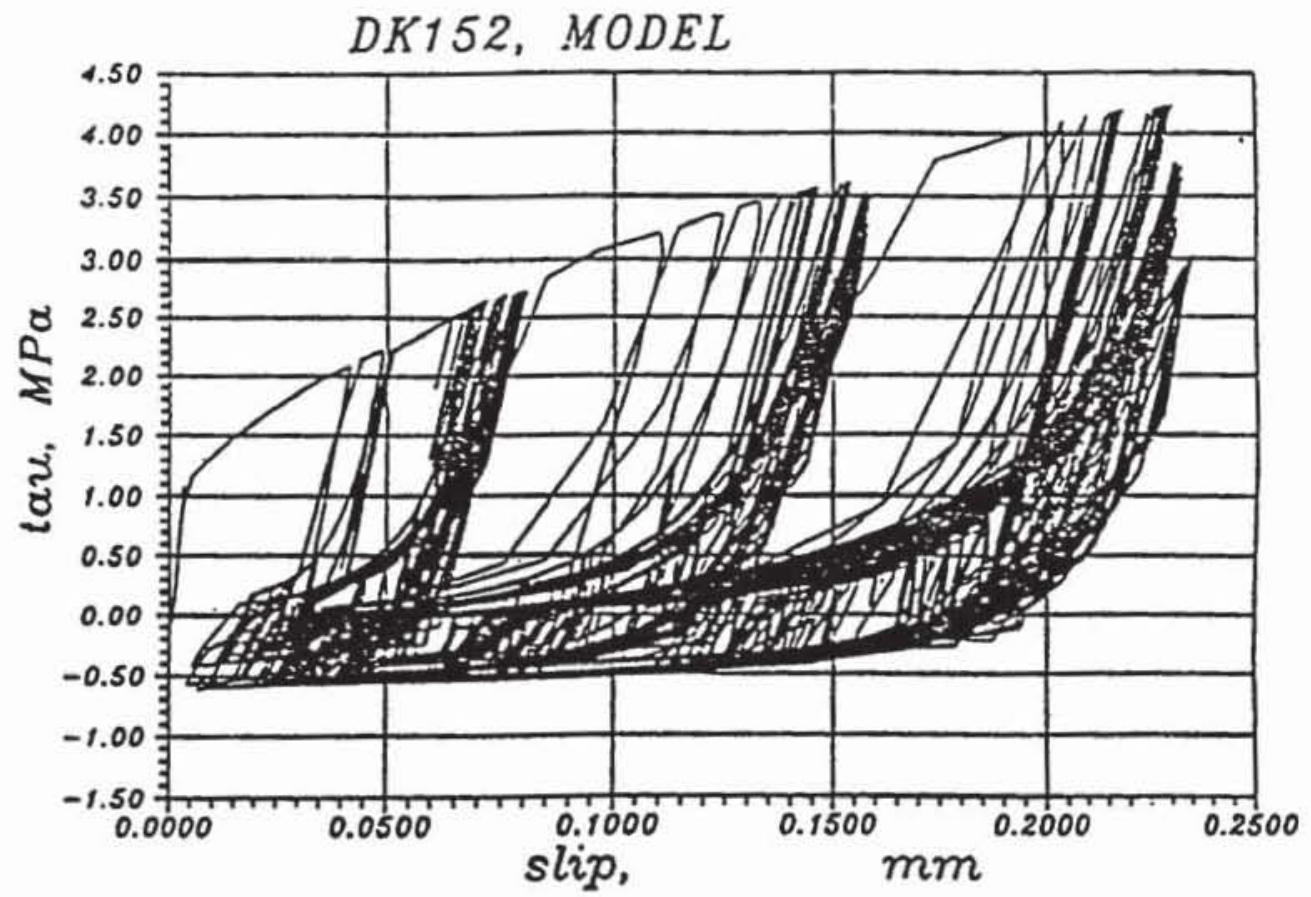

Fig.9 Bond stress-slip relationships; Fehling [31] 
loading, represents an intermediate step between load and slip controlled cycles and is characterized by a wide frequency content.

Previous state-of-the-art reports close to the present field are references [4], [15], [16], [17] and [18]. Extensive studies considering several parameters are presented in References [5],[13] and [19] to [28]. The main characteristics and some modelling possibilities are summarized in the following.

\subsubsection{Behaviour}

Cycles with reversed loading produce degradation of bond strength and bond stiffness that is more severe than for the same number of cycles with unidirectional loading [18], [24]. Degradation primarily depends on the peak slip in either direction reached previously [5] (Fig.10). Other significant parameters are the number of cycles and the difference between the peak values of slip between which the bar is cyclically loaded. Under otherwise constant conditions the largest deterioration will occur for full reversals of slip.

Whenever the load cycles are limited to produce slip only in one direction, there is no significant degradation of the bond strength [21] (Fig.11.a).

If the peak bond stress during cycling does not exceed $70-80 \%$ of the monotonic bond strength $\tau$, the ensuing bond stress-slip relationship at first loading in the reverse direction and at slip values larger than the one at which the specimen was cycled, is not significantly affected by up to 10 repeated cycles [5] (Fig.10.a). The bond resistance at peak slip deteriorated moderately with increasing number of cycles.

Loading to slip values inducing a bond stress larger than $80 \%$ of the monotonically obtained bond strength in either direction leads to degradation in the bond stress-slip behaviour in the reverse direction [5] (Fig.10.b and c). As the peak slip increases, deterioration of bond resistance is increased. Deterioration also increased as the number of cycles increased, and was larger for full reversals of slip than for half cycles (Fig.11).

Slip-controlled load reversals produce deterioration both of the peak bond stress and that of the frictional bond stress [24] (Fig.12).

Force-controlled load reversals produce a remarkable slip increase which demonstrates a more pronounced damage in concrete matrix around the steel bar [24] (Fig.13). The higher the load, the higher the slip increment. 
a.)

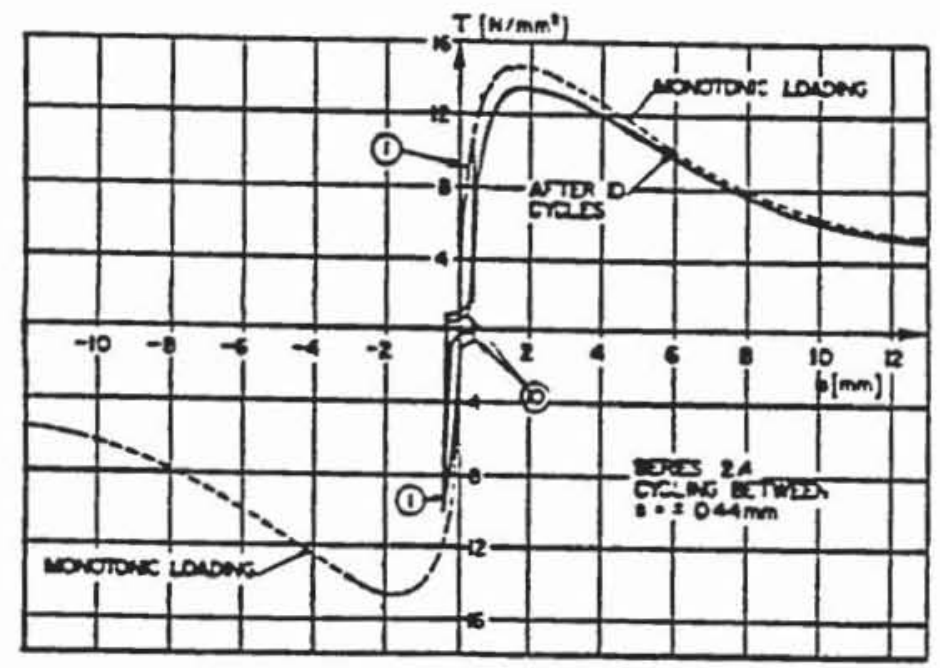

b.)

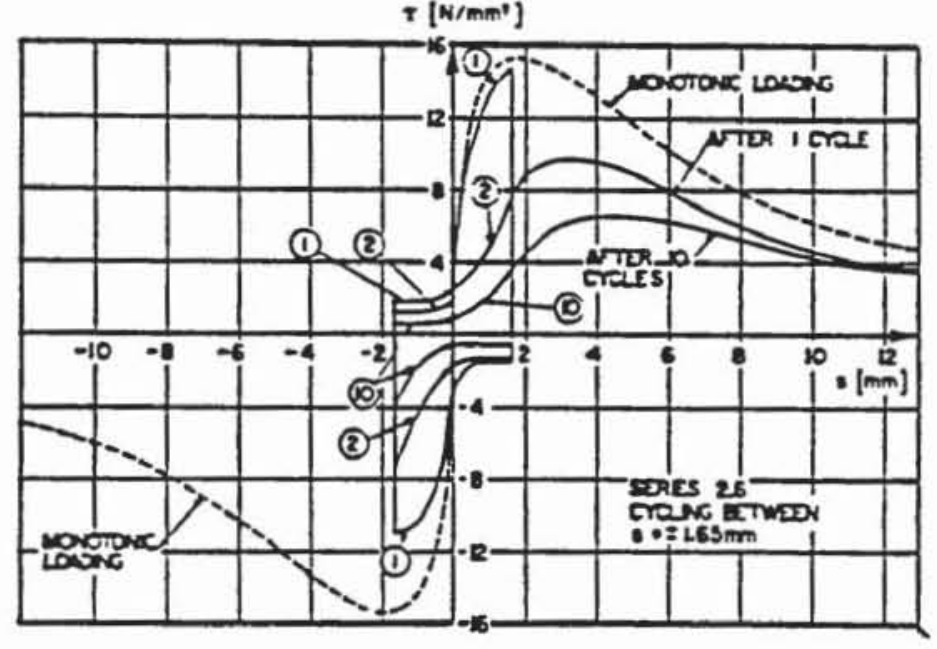

c.)

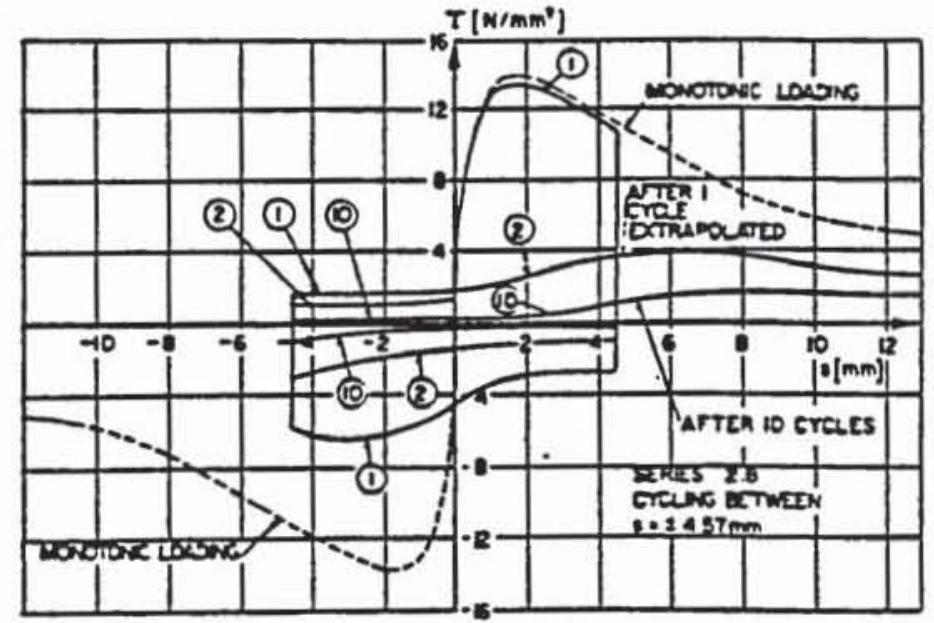

Fig.10 Bond stress-slip curves for cycling at different maximum slips; Eligehausen, Popov and Bertero [5] 

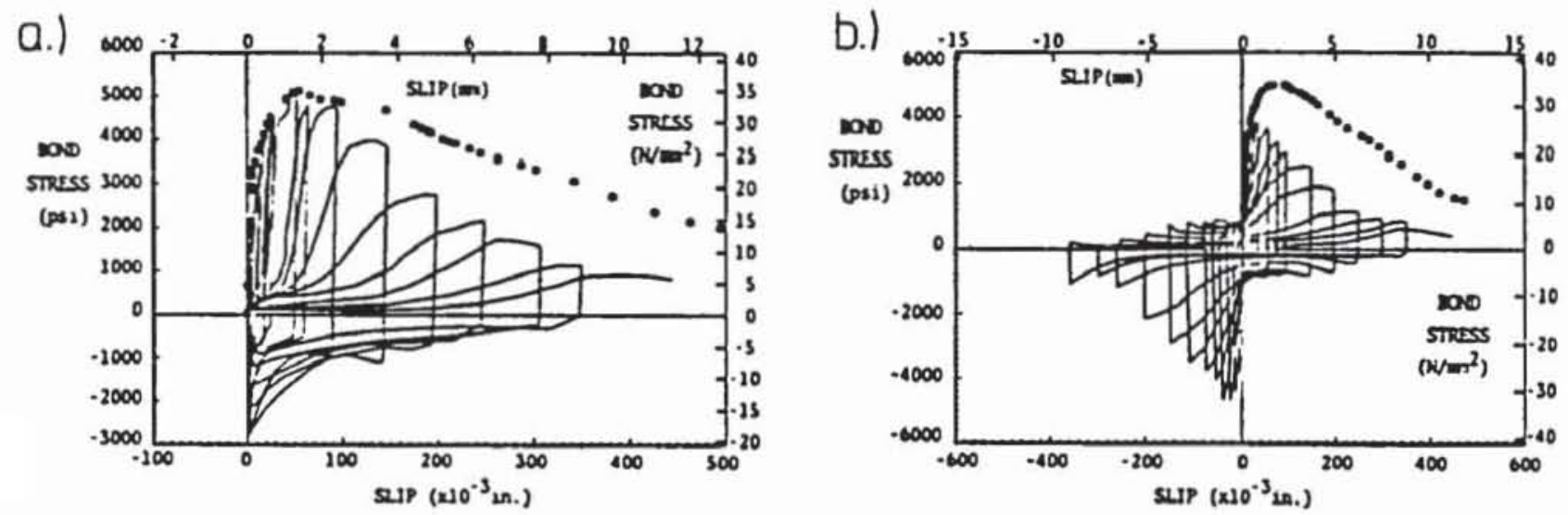

Fig. 11 Comparison of monotonic and reversed cyclic bond stress-slip curves without change of slip sign (a) and with change of slip sign (b); Hawkins, Lin and Jeang [22]

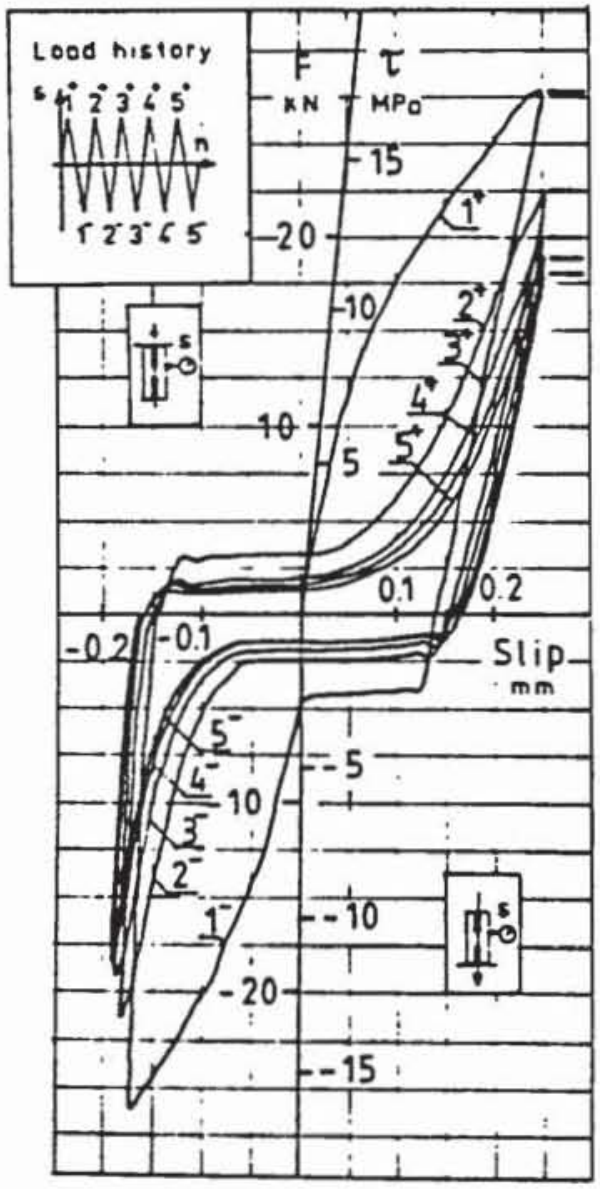

Deterioration of peak bond stress

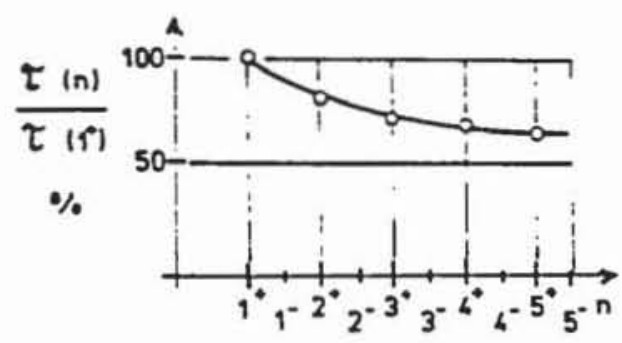

Deterioration of frictional bond stress

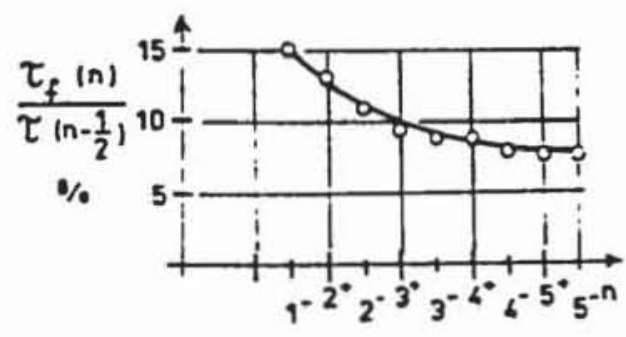

Fig.12 Slip-controlled load reversals, test result: $\phi 16$ def. bar $I_{b}=2 \phi, C$ 16; Balazs [24] 
Cycling a specimen at different increasing values of slip has a cumulative effect on the deterioration of bond stiffness and bond resistance indicated by the decrease of bond strength and the slip to the bond strength, respectively (Fig.10, Fig.11.b, and Fig.14).

Some additional cycles between smaller slip values than the peak value in the previous cycle do not significantly influence the bond behaviour at larger peak values.

The interactional behaviour under reversed cyclic loading (including also monotonic loading) may be followed by the following reasoning given by Eligehausen, Popov and Bertero [5].

When loading for the first time, the assumed bond stress-slip relationship follows the "monotonic envelope", which is valid for monotonically increasing slip (path $O A B C D$ in Fig.15). The initial slope, all other variables being equal, depends on the related rib area. At low bond stresses (point $\mathrm{A}$ ), inclined cracks begin to propagate from the top of the ribs; their growth and size is contained by the confining pressure provided by e.g. transverse reinforcement. Transfer of forces will be mostly by bearing, with a shallow angle of inclination ( $\alpha=30$ degrees, Fig.15). Increasing the load, local crushing of concrete in front of the lugs produces reduction of the tangent of the bond stress-slip curve (point B). When the maximum bond stress is attained the concrete key is sheared off, forming a cone with a length of about four times the lug height. At this point the line of action of the force is at an angle of about 45 degrees. With increasing slip the bond stress will begin to drop slowly. As the bond shear cracks reach the bottom of the adjacent lug (Point $D$ ) the bond stress begins to drop, and by the time the slip has reached the lug spacing only the frictional component remains (Point E).

Under load reversals (Fig.16), the initial loading follows the monotonic curve, but the cyclic load behaviour is sensitive to the level of slip at which the reversal occurs. Three possible qualitative models have been proposed, depending on whether or not inclined cracks have formed. In the first case (Fig.16.a) imposing a slip reversal at an arbitrary slip value below the level where inclined cracking occurs, results in a stiff unloading branch (path AF) because only a small part of the slip is caused by inelastic concrete deformations. As soon as slip in the opposite direction is imposed, the friction branch is reached (path FH). The slope of this portion of the curve is small because the surface of the concrete surrounding the bar is smooth. As soon as the cracks close, the stiffness differs little from that of the monotonic envelope (Point I). 


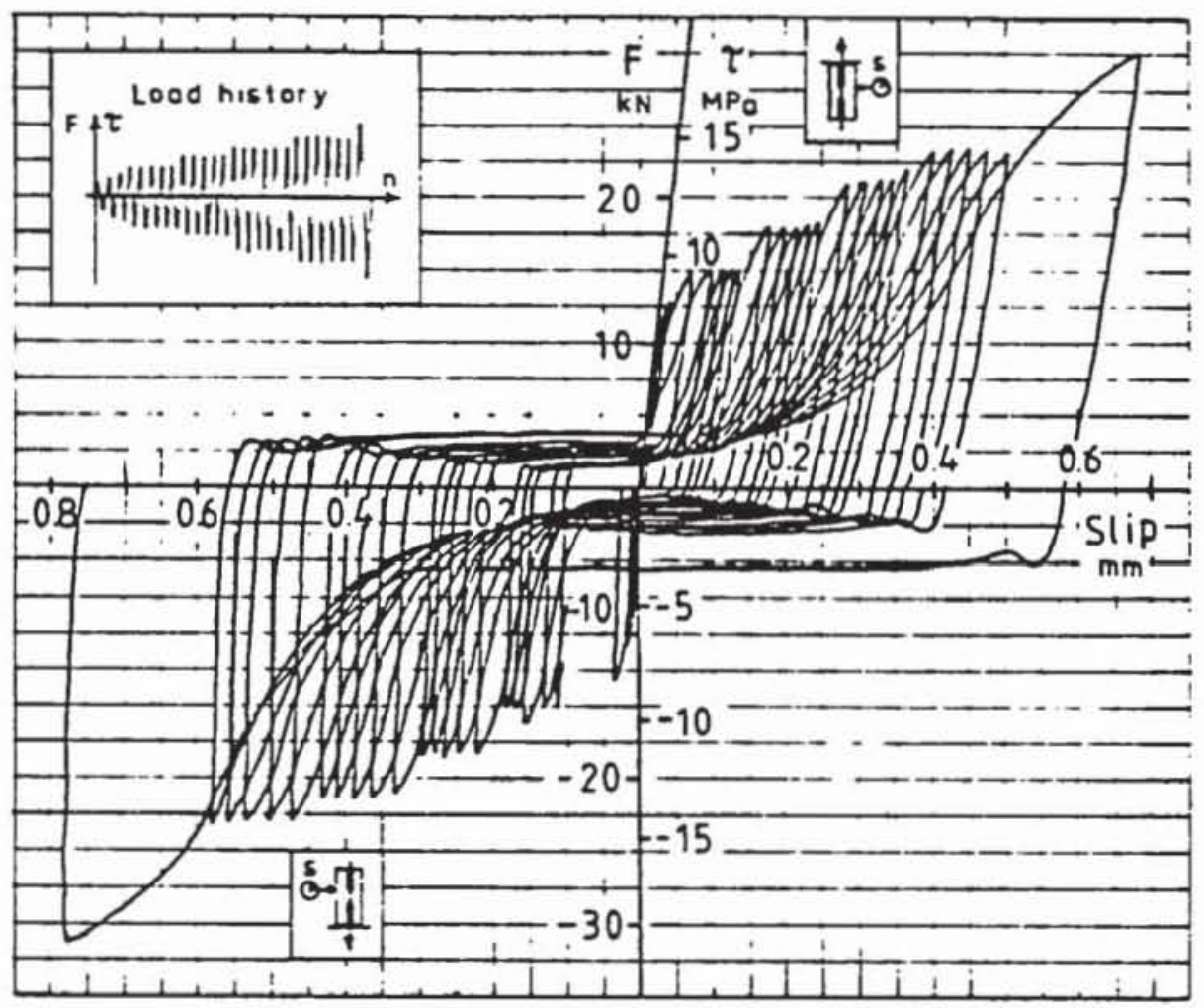

Fig.13 Force-controlled load reversals on four different load levels, test result: $\phi 16$ def.bar, $l_{b}=2 \phi, C 25 ;$ Balazs [24]

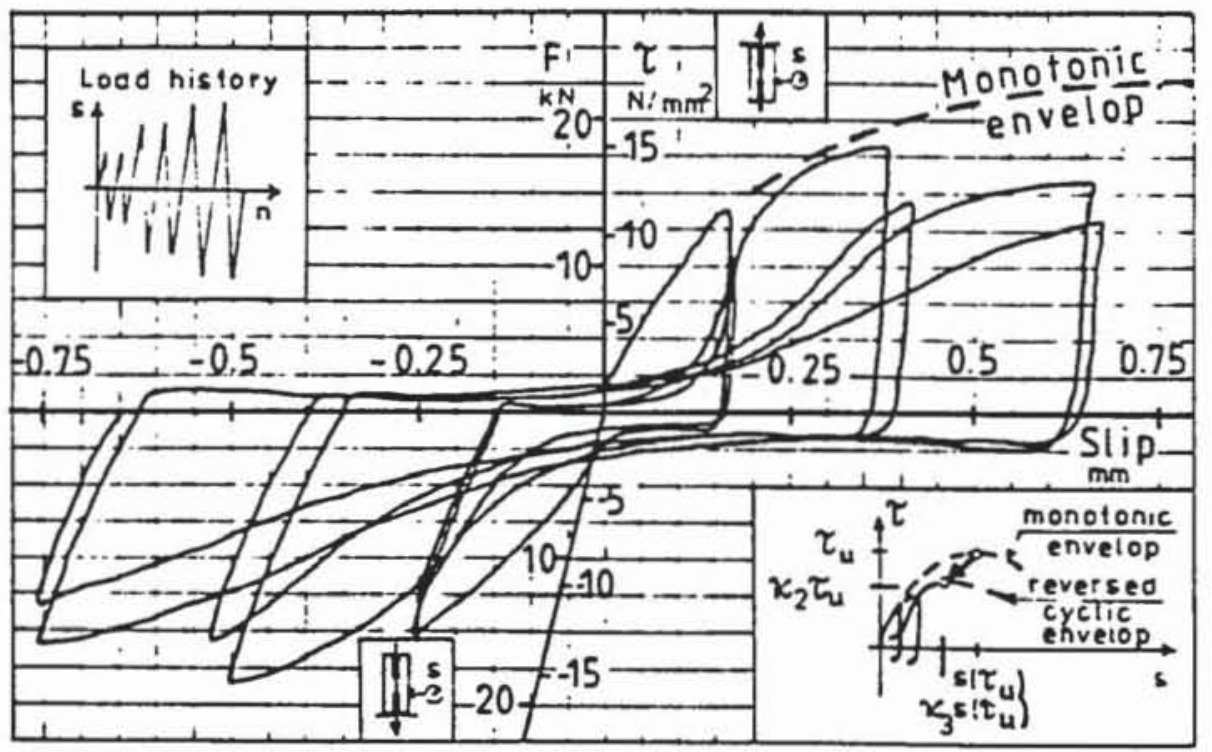

Fig.14 Bond deterioration under increasing reversed cyclic slip values, test result: $\phi 8$ def.bar, $l_{\mathrm{b}}=6 \phi, C 25 ;$ Balás [13] 
(a)
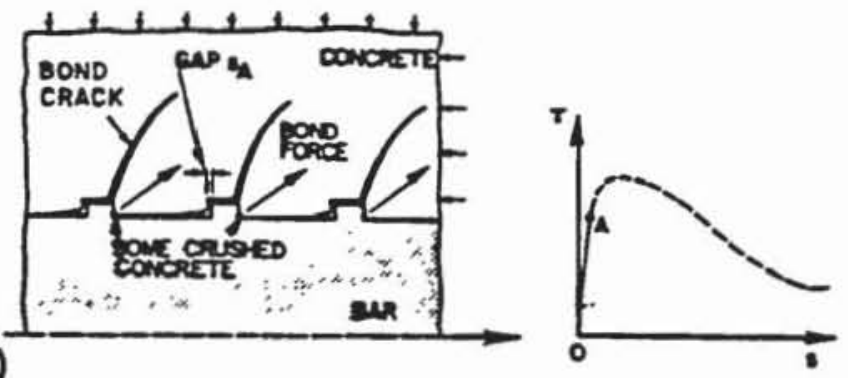

(b)
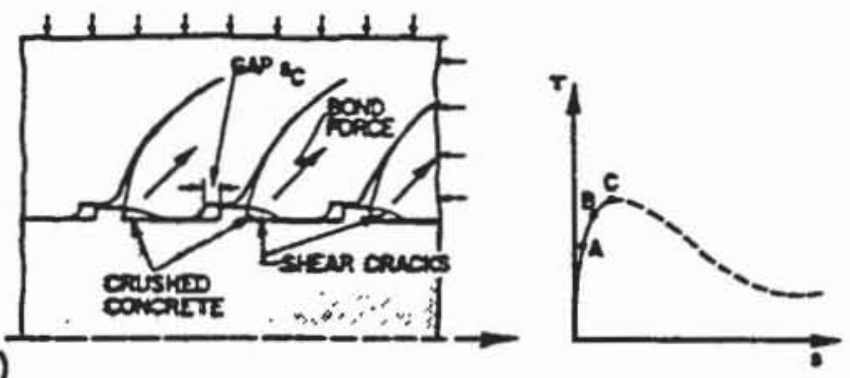

(c)
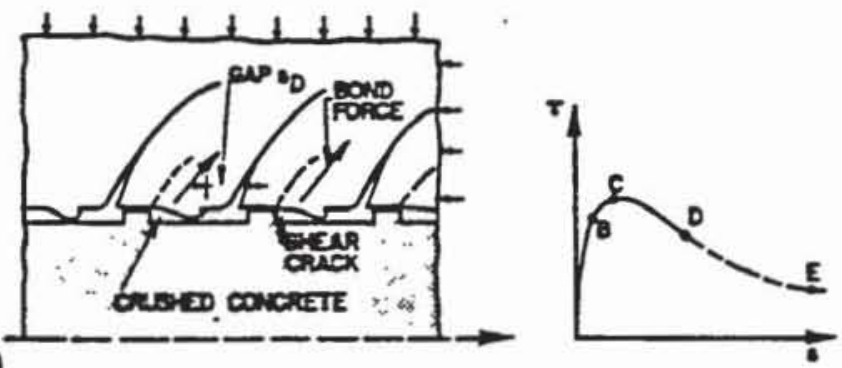

Fig.15 Bond mechanism under monotonic loading; Eligehausen, Popov and Bertero [5]

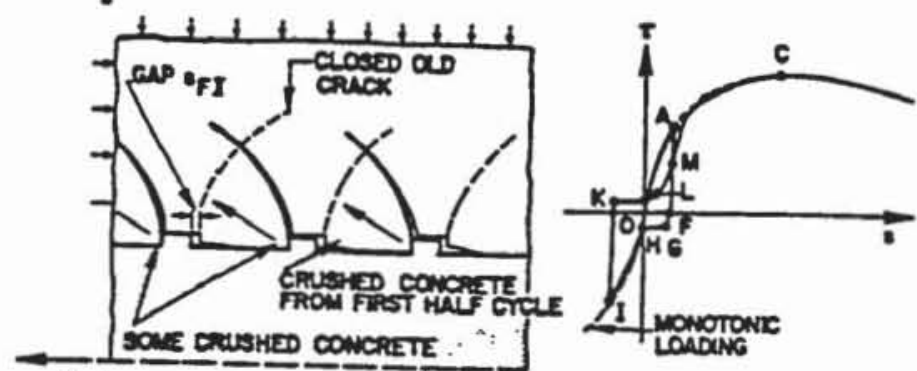

(a)

Fig.16 Bond mechanism underreversed cyclicloading; Eligehausen, Popov and Bertero [5]

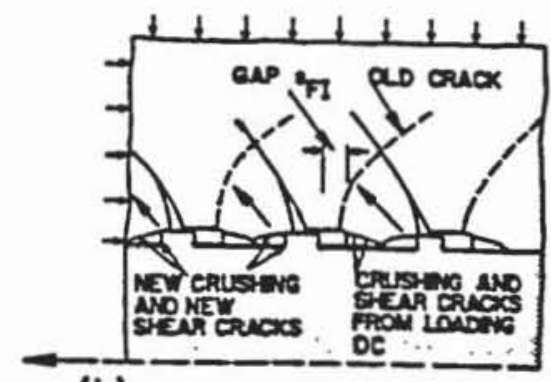

(b)

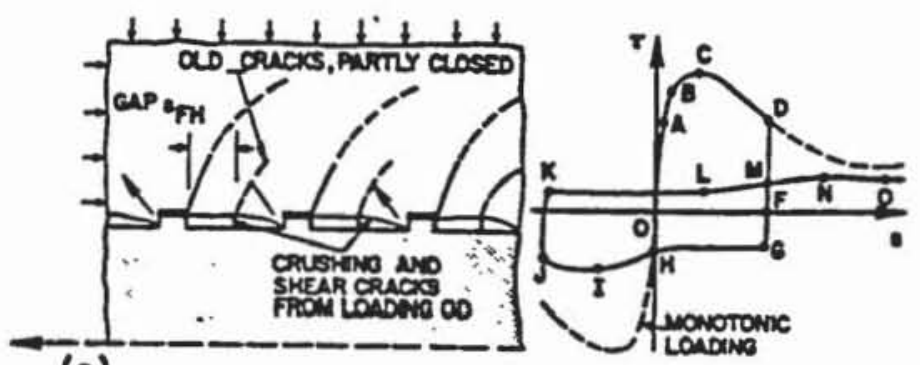


Unloading from point $\mathrm{I}$, where the slip in the two directions is about equal, the curve (path IKL) is very similar to that of the initial unloading curve (AFH). The major difference is that due to previous cracking and crushing of the concrete in front of the ribs, the point where the bond stresses begin to pick up again (point $\mathrm{L}$ ) will be shifted to the right of the origin. The lug will not be bearing fully until point $M$ is reached. Further loading follows the bond-slip curve up to the monotonic envelope.

If unloading occurs after the inclined cracks have formed (Fig.16.b), and therefore near the slip at which ultimate bond stress has been attained, the unloading path is similar to that of the first case up to point F. Since there is more damage to the concrete, a higher frictional resistance is mobilized (point $G$ ). When the loading is reversed the lug presses against a key whose resistance has been lowered by inclined cracks over a part of its length that were induced by the first half cycle. The splitting cracks created in the first half cycle close at a higher load than those of the first case (Point $\mathrm{H}$ ), and lead to an earlier formation of splitting cracks in the opposite direction. Splitting cracks, combined with the existing inclined cracks along the bar, result in a reduced envelope (Path $\mathrm{HI}$ ) and a reduction of bond capacity in the second direction (Point I). Unloading from this peak (Path IKLMN) and reverse the load results in a reduced stiffness and strength because only the remaining uncrushed concrete between the lugs must be sheared off. The bond strength (point $N$ ) is substantially lower than that of point $\mathrm{C}$, and lower than that of path I.

If unloading occurs after the slips has reached a value much larger than the slip at maximum strength (Point C), the behaviour will be very poor (Fig.16.c). Since more damage has occurred, the frictional resistance (Point $G$ ) will be larger than for either case I or II. However, since the concrete between the lugs is completely sheared very little force can be transmitted by bond when direction of loading is reversed (path HI). Unloading and reloading in the opposite direction (path JKLMN) results in very little additional bond capacity beyond that provided by friction since most of the mechanical anchorage has been lost.

\subsubsection{Analytical models}

Analytical models for bond behaviour under reversed cyclic actions are intended to be presented in the order of increasing efficiency in use. An approach for the monotonic envelope is presented in Section 4.2. 
The first analytical model of the bond stress-slip relationship for reversed cyclic loading was proposed by Morita and Kaku [19].

\subsubsection{Model by Morita and Kaku [19]}

The monotonic envelopes, which are different for loading in tension or compression and for confined or unconfined concrete are given by two successive straight lines which follow closely the experimentally measured curve (Fig.17). The assumed bond stress-slip relationship for the first cycle coincides relatively well with the behaviour observed in experiments. However, the observed deterioration of the bond resistance at peak slip and of the frictional bond resistance with increasing number of cycles is not taken into account. After cycling between arbitrary slip values, it is assumed that the monotonic envelope is reached again at slip values larger than the peak value in the previous cycle and followed thereafter.

The model is sufficiently accurate for a small number of cycles between relatively small slip values with corresponding bond stresses smaller than about 80 percent of monotonic $\tau_{\max }$. However, it is inaccurate for several load cycles, and it is not valid for slip values larger than the one corresponding to $0.8 \tau_{\max }$.

\subsubsection{Model by Tassios [16]}

At the begining of loading, up to point $\mathrm{A}$ in Fig.18, the bond resistance is developed by adhesion. Further loading produces high compressive stresses in the concrete in front of the lugs and hoop tensile stresses around the bar leading to inclined micro-cracks (point B). When these cracks reach the concrete surface, say at point $\mathrm{C}$, the bond resistance may drop to zero in lack of confining reinforcement. However, if concrete is well confined, the load can be increased till point $D$, where shearing off the concrete between the bar lugs initiates. The same bond stress-slip relationship is assumed regardless of whether the bar is pulled or pushed.

During cycling, loading to a slip value $s>s_{B}$, the values of $\tau$ of the bond stress-slip relationship for loading in the reversed direction are reduced by $1 / 3$ compared to the monotonic envelope. The bond stress-slip relationship for reloading and for subsequent cycles between fixed slip values is somewhat simplified compared 


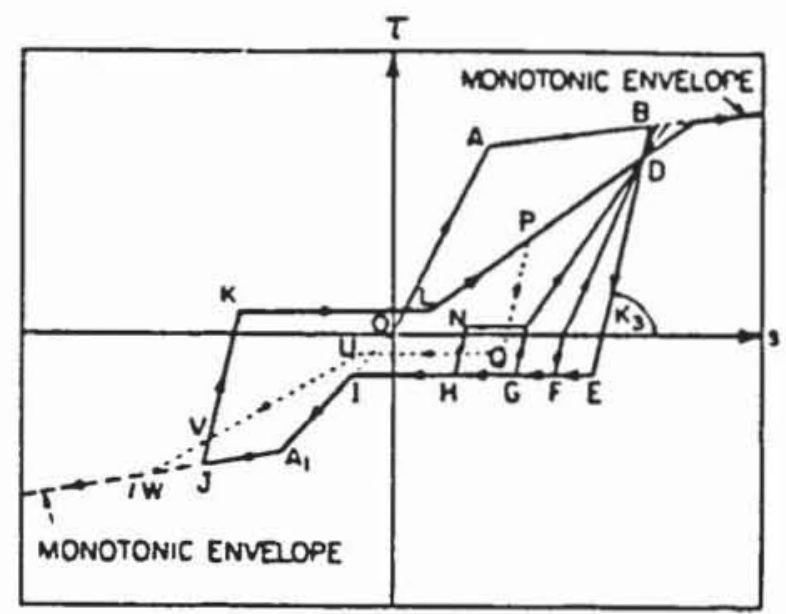

$$
\begin{aligned}
& T_{D}=\beta \cdot T_{B} \quad T_{K}=\alpha \cdot T_{J} \quad z_{L} \cdot\left(s_{B}+B_{j}\right) / 2 \\
& T_{V}=\beta \cdot T_{J} \quad T_{N}=\alpha \cdot T_{H} \quad s_{U}=\left(s_{j}+s_{p}\right) / 2 \\
& T_{E}=\alpha \cdot T_{B} \quad T_{0}=\alpha T_{p} \quad s_{G} \cdot s_{\theta} / 2 \\
& K_{3}=400 \mathrm{~N} / \mathrm{mm}^{3} \\
& \text { a. } 018 \\
& B=0.9 \\
& \text { B = 09-044(s-0.05) 005s } 3505 \mathrm{~mm}
\end{aligned}
$$

Fig.17 Reversed cyclic bond stress-slip relationship proposed by Morita and Kaku [19]
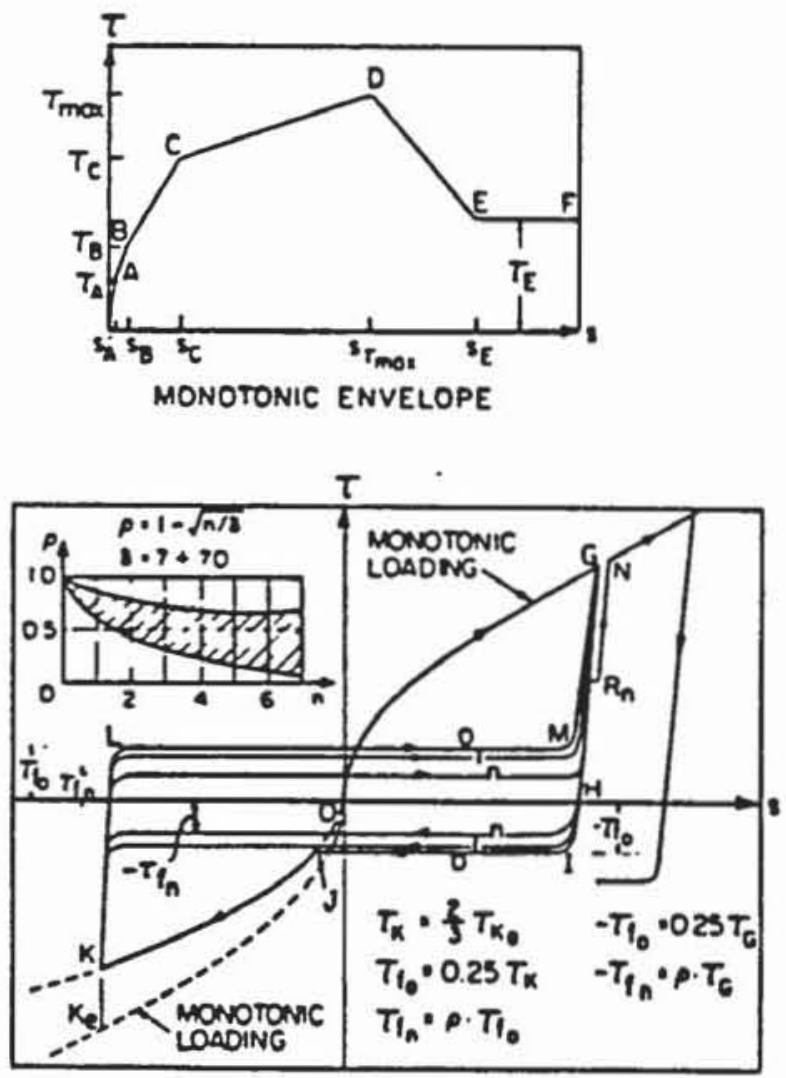

Fig.18 Bond model proposed by Tassios [17] 
to the real behaviour. However, the deterioration of the bond resistance at peak slip and of the frictional bond resistance is taken into account. When increasing the slip beyond the cyclic peak value ( $s>s_{G}$ in Fig.18), it is assumed that the monotonic envelope is reached again.

Tassios' model is an improvement compared to the older one of Morita and Kaku insofar as the descending branch of the local bond stress-slip relationship is given and the influence of load cycles on bond deterioration for slip values smaller than or equal to the peak slip value of the previous cycle is taken into account. However, the assumption that for slip values larger than the peak value in the previous cycle the monotonic envelope is reached again and followed thereafter, while the bond stresses in the reversed direction are reduced by $1 / 3$ compared to the monotonic envelope, is not sufficiently accurate. For monotonic loading, the model is useful for the total slip range. However, for cyclic loading it is valid for slip values $s<<s_{\gamma_{\max }}$ only. The deterioration of bond resistance was studied in a following paper by Plaines, Tassios and Vintzeleou [23].

\subsubsection{Model by Viwathanatepa, Popov and Bertero [25]}

(a) A four stage piecewise linear approximation is used as monotonic envelope (Fig.19). The physical meaning of the controlling points are the same as described in Section 4.4.1. However, points B and C (occurrence of internal bond cracks and splitting cracks) are omitted. Different monotonic envelopes are assumed for unconfined concrete in tension, confined conrete and unconfined concrete in compression, which simulate the behaviour observed in experiments (compareFig.1).

(b) Cycling between points $A$ and $A_{1}$ or unloading and reloading only (paths GIG or $\mathrm{KLK}$ ) do not deteriorate the envelope.

(c) Unloading from a point beyond $A$ or $A_{1}$ and following the friction path for an arbitrary small slip value produces reduced envelopes (OAD'E'F and $\mathrm{OA}_{1} \mathrm{D}_{1} \mathrm{E}_{1}{ }_{1} \mathrm{~F}^{\prime}{ }_{1}$ ) by reducing the characteristic bond stresses $\tau_{\mathrm{D}}, \tau_{\mathrm{D} 1}, \tau_{\mathrm{E}}, \tau_{\mathrm{E} 1}$ and the slip values $s_{E}, S_{E}$ by a reduction factor. The latter depends on the cumulative slip having magnitudes larger than those of the previous cycle. Therefore, no further reduction of the envelope is assumed for subsequent cycles 


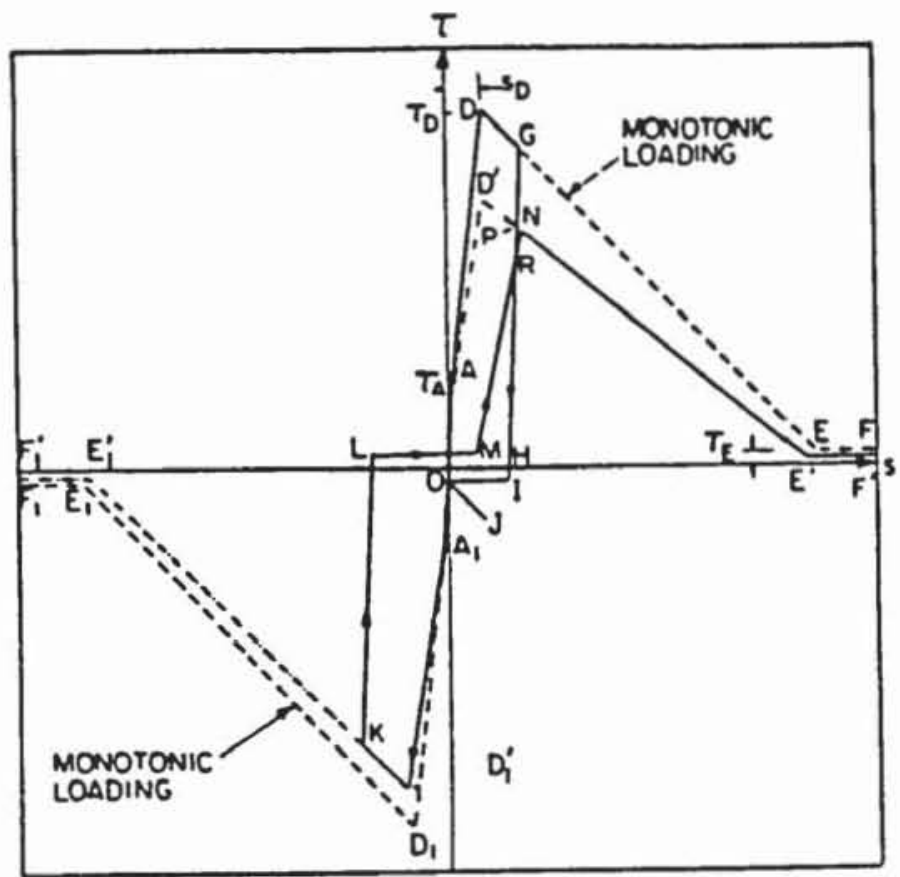

$$
\begin{array}{llll}
T_{1}=\tau_{E_{1}} & T_{A}=0.9 T_{P} & T_{D^{\prime}}=\alpha_{D} \cdot T_{D} & T_{D_{i}}=\alpha_{D}^{\prime} \cdot T_{D_{1}} \\
T_{L}=T_{E} & s_{M}=04 s_{G} & T_{E}=\alpha_{E} \cdot T_{E} & T_{E_{i}^{\prime}}=\alpha_{E}^{\prime} \cdot T_{E_{1}} \\
& & s_{E}=\beta_{E} \cdot s_{E} & s_{E_{i}}=\beta_{E}^{\prime} \cdot s_{E_{1}}
\end{array}
$$

$\alpha, \alpha^{\prime}, \beta, \beta^{\prime}$ : FUNCTION OF LOADING HISTORY

Fig.19 Reversed cyclic bond stress-slip relationship proposed by Viwathanatepa, Popov and Bertero [25]

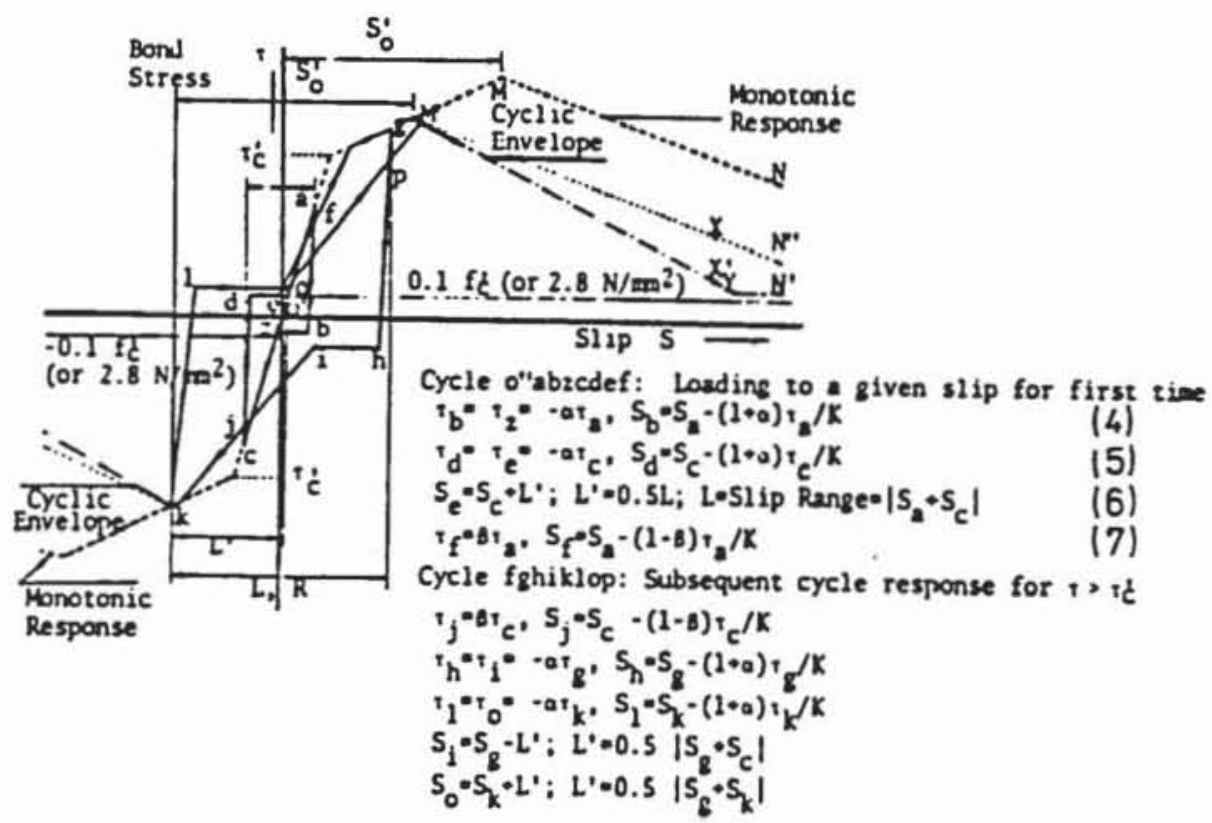

Fig.20 Local bond stress-slip rules for cyclic loading proposed by Hawkins, Lin and Jeang [22] 
between slip values smaller than or equal to the previous peak slips.

As an example, Eq.(1) gives the reduction of $\tau_{0}$. Similar equations exist for the reduction of the other characteristic values which describe the model.

$$
\tau_{D}=\alpha_{D} \cdot \tau_{D}=\left(1-\alpha_{T D} \frac{\Sigma s_{i} / S_{D}}{P_{D}} \cdot \xi_{T D}-B_{T D} \frac{\Sigma s_{i 1} / S_{D}}{P_{D}} \cdot \xi_{T D}\right) \tau_{D}
$$

$\Sigma s_{i}, \Sigma s_{i l}$ : sum of the peak slip values having a magnitude larger than in the previous cycles for loading in tension or compression, respectively;

$S_{0}$ : slip at point $D ;$

$\alpha_{T D}, B_{T D}, \xi_{T D}, P_{D}$ : constants, evaluated from test results.

(d) The frictional bond resistance is assumed to be equal to $\tau_{\mathrm{E}}$ of the monotonic envelope and independent of the number of cycles.

(e) The bond stress-slip relationships for the reloading branch (path MRN) and for additional cycles between fixed slip limits are very similar to those proposed in [19].

The above model is a major improvement, because it takes several features observed in experiments into account and it is approximately valid for cycling between arbitrary slip values. However, in spite of being rather complicated, it is not general. Some 20 parameters are needed to describe the bond stress-slip relationship for cyclic loading, which have no clear physical meaning and must be evaluated from test results. Furthermore, the assumptions on which the calculation of the reduced envelope is based need improvement. For example, an arbitrary number of cycles $(\geq 1)$ in well-confined concrete between $s_{\max }=2_{s 0}$ and $s_{\min }=-2_{\text {so }}$ reduces $\tau_{0}$ independent of the number of cycles by 13 percent. On the contrary to that $\tau_{D}$ is reduced to zero after eight cycles between almost the same peak slip values if only the value of $s_{\max }$ is slightly increased in each cycle. 


\subsubsection{Model by Hawkins, Lin and Jeang [22]}

The monotonic envelope is idealized by a tri-linear bond stress-slip diagram. The characteristic values of slips, bond stresses and tangents are obtained by statistical evaluation of the test data yielding to three linear equations [22].

During load reversals, deterioration in the loading envelope does not begin until the slip range exceeds $s^{\prime}{ }_{0}$, where $s^{\prime}{ }_{0}$ is the slip for $\tau_{\max }$ for monotonic loading. The deteriorated capacity in the positive direction follows the line $\mathrm{M}^{\prime} \mathrm{X} \mathrm{X}^{\prime} \mathrm{YN}$ ' where that line is derived from the line $\mathrm{M}^{\prime} \mathrm{XN}$ ' that parallels line MN (Fig.20). The post-peak response envelope for the negative direction mirrors that for the positive direction. Rules for deriving the post-peak response envelope for the positive direction are:

$$
\begin{aligned}
& \mathrm{s}_{\mathrm{K}}=\mathrm{s}_{\mathrm{W}^{\prime}}=\mathrm{s}_{\mathrm{K}^{\prime}}=0.5\left(\mathrm{~s}_{\text {lug }}+\mathrm{W}\right) \\
& \mathrm{s}_{\mathrm{X}}=\mathrm{s}_{\mathrm{X}^{\prime}}=0.45 \mathrm{~s}_{\text {lug }}=0.5\left(\mathrm{~s}_{\text {lug }}-\mathrm{W} / 2\right) \\
& \tau_{\mathrm{X}^{\prime}}=0.45 \tau_{\mathrm{X}} \text { but } \tau_{\mathrm{X}^{\prime}} \geq 0.1 \mathrm{f}_{\mathrm{c}} \text { or } 2.8 \mathrm{~N} / \mathrm{mm}^{2} \\
& \mathrm{~s}_{Y}=0.50 \mathrm{~s}_{\text {lug }} ; \tau_{Y} \geq 0.1 \mathrm{f}_{\mathrm{c}}^{\prime} \text { or } 2.8 \mathrm{~N} / \mathrm{mm}^{2} \\
& \tau=\tau_{Y}-0.5\left(\mathrm{~s}-\mathrm{s}_{\mathrm{Y}}\right), \mathrm{s}_{\mathrm{Y}} \leq \mathrm{s} \leq \mathrm{s}_{\mathrm{W}}
\end{aligned}
$$

where $s_{\text {lug }}=$ lug spacing, and $\mathrm{W}=$ lug width.

The rules for unloading and the construction of loading loops are also shown in Fig.20. That response is defined by the unloading stiffness, $\mathrm{K}$, and coefficients $\alpha$ and $B$, which define, respectively, the stress level for marked slip under reversal of loading, and the degeneration in capacity for one loading cycle between given slip limits. Statistical analyses of the test data, and round-off of the resulting coefficients gave the following values:

$$
\begin{aligned}
& \mathrm{K}=260 \mathrm{~N} / \mathrm{mm}^{2} \\
& \alpha=0.15
\end{aligned}
$$


$B=0.9$ when $\tau$ has not exceeded $\tau^{\prime}$ c

$0.9 \geq B=5\left(s-s_{c}^{\prime}\right) \geq 0.65$ when $\tau$ has exceeded $\tau_{c}^{\prime}$

In Fig. $20 \mathrm{k}, \mathrm{c}, \mathrm{z}, \mathrm{o}^{\prime \prime}, \mathrm{a}, \mathrm{g}, \mathrm{M}^{\prime}, \mathrm{M}$, and $\mathrm{N}$ are points on the monotonic loading envelope. The loop o"abzcdef defines the response for loading for the first time between given reversing slips. Egs.(4) through (7) (see Fig.20) define critical stress and slip values. The quantity $\mathrm{L}^{\prime}$ in Eq.(6) defines the magnitude of the marked slip under constant reversed stress. B is defined by Eq.(2). The loop efghiklop defines the response for loading in a second or subsequent cycle to increased slips when $\tau$ has exceeded $\tau^{\prime}{ }_{c}$ in a previous cycle. Initially, the response for $\tau>\tau_{f}$ is defined by the extension of line ef to the monotonic envelope. Unloading rules from $g$ to $h$ and $\mathrm{k}$ to $\mathrm{l}$ are the same as those for a to $\mathrm{b}$. Loading reversal rules from $\mathrm{h}$ to $\mathrm{i}$ and $\mathrm{l}$ to $o$ are the same as those from $d$ to e. Since $\tau$ has exceeded $\tau_{c}^{\prime}, B$ is defined by Eq.(3).

The foregoing rules for loop construction must be modified slightly for type 1 cyclic loading (like Fig.11.a). If the slip range has not exceeded s'。 and the slips for negative loading have not exceeded $-0.08 \mathrm{~mm}$, then the response in the negative loading direction is of the friction type before intersection with the monotonic envelope, and follows the monotonic envelope after intersection. If the slip range has not exceeded s'。 but the slips for negative loading have exceeded $-0,08 \mathrm{~mm}$, then the loop construction rules are the same as those for type 2 loading (like Fig.11.b) except that $B$ values for the negative loading direction must be modified as follows:

$$
\begin{aligned}
& B=0.9 \text { when } s \text { has not exceeded } s^{\prime} \text { 。 } \\
& B=0.65 \text { when } s \text { has exceeded } s^{\prime} \text { 。 }
\end{aligned}
$$

According to the proposal, for cyclic loading the bond stress-slip envelope is similar to that for monotonic loading prior to attainment of the maximum capacity. At the maximum capacity, the bond effectiveness for cyclic loading is less than for monotonic loading with the decrease in capacity being greater for fully reversed cyclic loading than for zero to a maximum slip cyclic loading. After attainment of the maximum capacity, the bond stress for a given displacement is always less than that for monotonic loading although the rate of decrease in capacity with increasing slips is 
similar to that for monotic loading. The relatively complicated model intends to prescribe the characteristic bond stresses and the selected slip values during cycling with rules and factors obtained by tests applicable for small and also for high slip values. The ascending branch of the trilinear approach for the cyclic envelop give reasonable values for slips higher than in the previous cycle but a relatively rough approach for lower ones owing to the low loading moduls. Frictional bond stresses formulated as a function of the previously reached maximum bond stress does not satisfactorily follow force controlled reversed cycles.

\subsubsection{Model by Balázs [13]}

First loading produces micro-cracking and micro-crushing in the concrete matrix around the rebar. When loading in the subsequent cycles, the previous state is reproduced in a softer matrix followed by a more stiff concrete response. The physical change is represented by points of inflection. The points of inflection belong to the intersection of reloading branch and previous unloading branch close to the highest slip value before unloading. Hence, the first loading curves are concave in both directions, all subsequent loading curves are convex (following the frictional portion) until the intersection point mentioned above, then become concave. As a consequence, the shape of the ascending branch of any possible reversed cyclic bond stress-slip curve indicates whether higher slip values during the previous load history occured or not. The answer is yes if a point of inflection is available, otherwise no.

Reversed cyclic loading produces reductions of both the bond strength $\left(\tau_{u}\right.$, obtained by monotonic test) and the related slip, $s\left(\tau_{\omega}\right)$.

The reduction depends on the actual load history, the number of reversed load cycles and the maximum previous slip (Fig.21). Ranges of reduction factors form the test results are: $x_{1}=0.9$ to 1.0 for the monotonic envelope in the secondary loading direction, $x_{2}=0.7$ to 1.0 for the bond strength and $x_{3}=0.5$ to 1.0 for the slip at monotonic bond strength.

Assuming a symmetrical reversed cyclic load history, the maximum bond stress , $0.7 \tau_{u}$, is observed by a slip of $0.5 s\left(\tau_{\omega}\right)$. Hence $0.5 \mathrm{~s}\left(\tau_{\omega}\right)$ provides a fatigue failure criterion.

The softening of bond during a slip-controlled test is represented by the decrase of the maximum bond stress itself. During a forcecontrolled test the softening is 


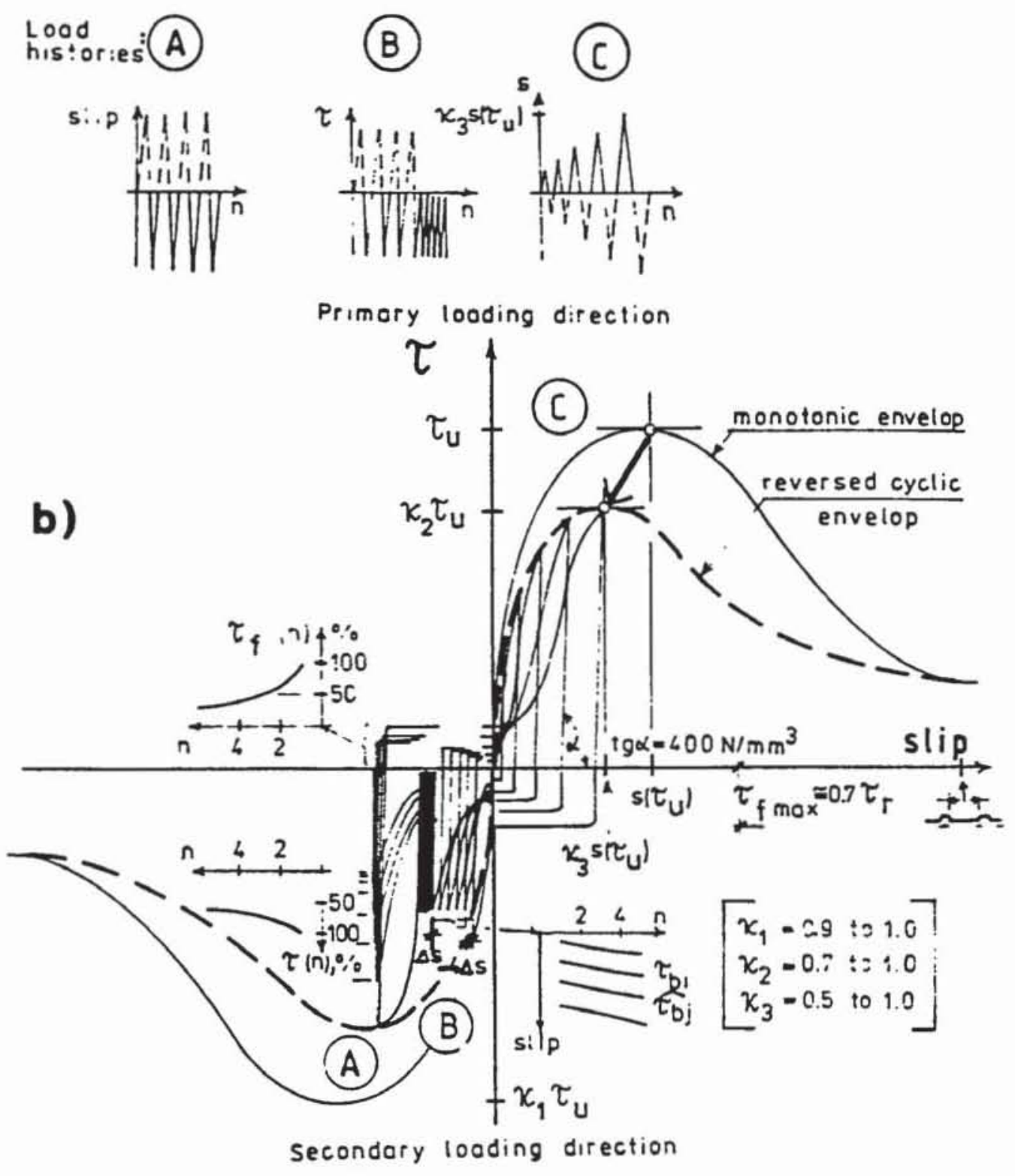

Fig.21 Bond fatique behaviour under reversed cyclic loading; Balbzs [13]

indicated by a remarkable slip increase. Following slip-controlled load reversals, the maximum bond stress decreases asymptomatically.

Frictional bond stress increases during force-controlled reversals and decreases during slip-controlled reversals, consequently the frictional bond stress is a function of the actual slip and of the number of previous load cycles. Its maximum value is approximately $70 \%$ of the residual bond stress obtained after the concrete between bar lugs are sheared off. 
The slip rate due to force-controlled load reversals is approximately 4 times higher in comparison to that of a unidirectional cyclic loading both having the same maximum value of cyclic force [24].

The model summarizes the characteristics observed in bond behaviour under slip controlled or force controlled load reversals. A reversed cyclic envelop is defined considering deterioration of both the bond strength and that of the related slip which can be a suitable solution to take into account the reduction in bond capacity. The frictional bond stress is considered as a function of actual slip reaching a maximuim value related to the residual bond stress. Guidance is given to compare the increase of slip values produced by cyclic or by reversed cyclic loading, respectively.

\subsubsection{Model by Ciampi, Eligehausen, Bertero and Popov [21]}

Their extensive experimental investigation concentrated on reversed cyclic bond behaviour for relatively large slip values [5], [20], [21].

The assumed bond model is illustrated in Fig.22. Although it simplifies the observed real behaviour, it takes into account the significant parameters that appear to control the behaviour observed in the experiments. The model's main characteristics, illustrated by following a typical cycle, are described below.

When loading the first time, the assumed bond stress $(\tau)$ - slip (s) relationship follows a curve valid for monotonically increasing slip, which is called herein monotonic envelope (paths $\mathrm{OABCD}$ or $\mathrm{OA}_{1} \mathrm{~B}_{1} \mathrm{C}_{1} \mathrm{D}_{1}$ ). Imposing a slip reversal at an arbitrary slip value, a stiff unloading branch is followed up to the point where the frictional bond resistance, $\tau_{f}$, is reached (path EFG). Further slippage in the negative direction takes place without an increase in $\tau$ up to the intersection of the "friction branch" with the curve $\mathrm{OA}_{1}$ (path GHI). If more slip in the negative direction is imposed, a bond stress-slip relationship similar to the virgin monotonic curve is followed, but with values of $\tau$ reduced as illustrated by the path $I A_{1} J$, which is part of the curve $\mathrm{OA}_{1} \mathrm{~B}_{1} \mathrm{C}_{1} \mathrm{D}_{1}$ that is called "reduced envelope". When reversing the slip again at $\mathrm{J}$, first the unloading branch and then the frictional branch, with $\tau=\tau_{f}$, are followed up to point $\mathrm{N}$, which lies on the unloading branch EFG (path JLN). At $N$ the "reloading branch" (same stiffness as the unloading branch) is followed up to the intersection with the reduced envelope $\mathrm{OA}^{\prime} \mathrm{B}^{\prime} \mathrm{C}^{\prime} \mathrm{D}^{\prime}$ (path $\mathrm{NE}$ '), which is followed thereafter (path E'B'S). If instead of increasing the slip beyond point $\mathrm{N}$ more cycles between the slip values corresponding to points $\mathrm{N}$ and $\mathrm{K}$ are imposed, the bond 


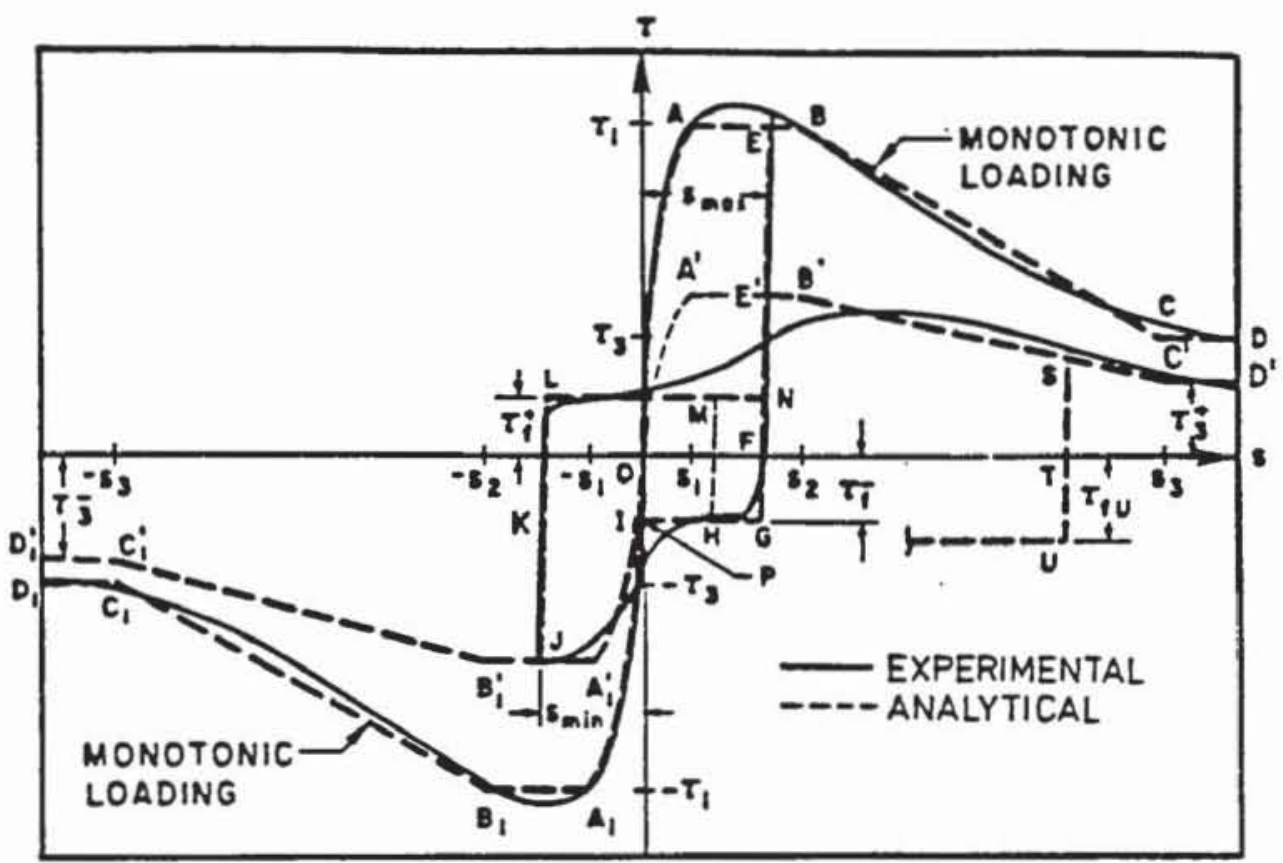

Fig.22 Proposed analytical model for local bond stress-slip relationship by Ciampi, Eligehausen, Bertero and Popov [21]

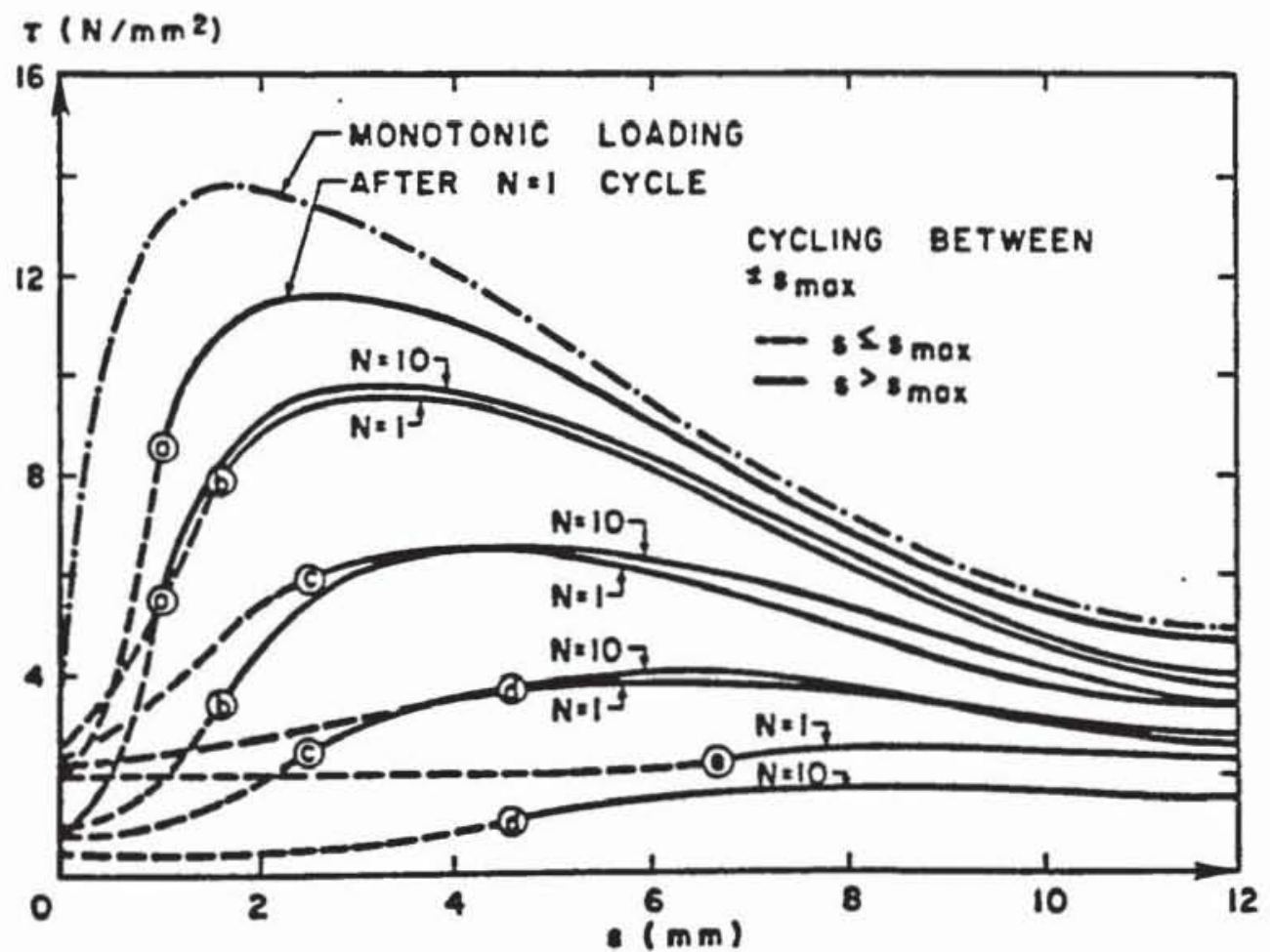

Fig.23 Effects of number of cycles and of the peak values of slip $s_{\max }$ at which the cycling is performed on the ensuing bond stress-slip relationship for $s>$ $s_{\max }$; Ciampl, Eligehausen, Bertero and Popov [21] 
stress-slip relationship is like that of a rigid plastic model, the only difference being that frictional bond resistance decreases with increasing number of cycles. A similar behaviour as described is followed if the slip is reversed again at point S (path STU). To complete the illustration of the model, details about the different branches referred to in the above overall description are given in the following sections.

The description of monotonic envelope is given in Section 4.2 and by Figs.1. and 2 , respectively.

Reduced envelopes are obtained from the monotonic envelope by decreasing the characteristic bond stresses $\tau_{1}$ and $\tau_{3}$ (see Figs.2 and 22) through reduction factors, which are formulated as a function of one parameter, called herein the "damage parameter $d "$. For no damage, $d=0$, the reloading branch reaches the monotonic envelope. For full damage, $d=1$, bond is completely destroyed $(\tau=0)$.

The rationale for this assumption is given by Fig.23, which shows that reloading curves for similar specimens, subjected to different loading histories, appear to form a parametric family of curves.

The deterioration of the monotonic envelope seems to depend on the damage experienced by the concrete, particularly the length of the concrete between the lugs of the bar that has sheared off. This, in turn, is a function of the magnitude of the slip induced in the bar in both directions, the larger the $s_{\max }$ and the difference between peak slip values, the larger the damage. Another influence factor is the number of cycles. These parameters can be related to the energy dissipated during the loading and unloading processes. Therefore, it was assumed that the damage parameter $d$ is a function of the total dissipated energy only. However, it has also been taken into account that only a fraction of the energy dissipated during subsequent cycles between fixed peak slip values appears to cause damage, while the other part appears to be used to overcome the frictional resistance and is transformed into heat.

Fig.24 illustrates the correlation between the measured damage factor, $d$, for tests with full reversal of slip as a function of the computed dimensionless dissipated energy factor $E / E_{0}$. The proposed function for $d$ is shown as well. In the computation of $\mathrm{E}$, only $50 \%$ of the energy dissipated by friction is taken into account. The normalizing energy $E_{0}$ corresponds to the absorbed energy under monotonically increasing slip up to the value $s_{3}$. Although there is some scatter, the agreement between the analytical and experimental results seem acceptable.

No reduction of the current envelope (monotonic or reduced) is assumed for unloading and reloading only. If a cycle is not completed to the current values of 


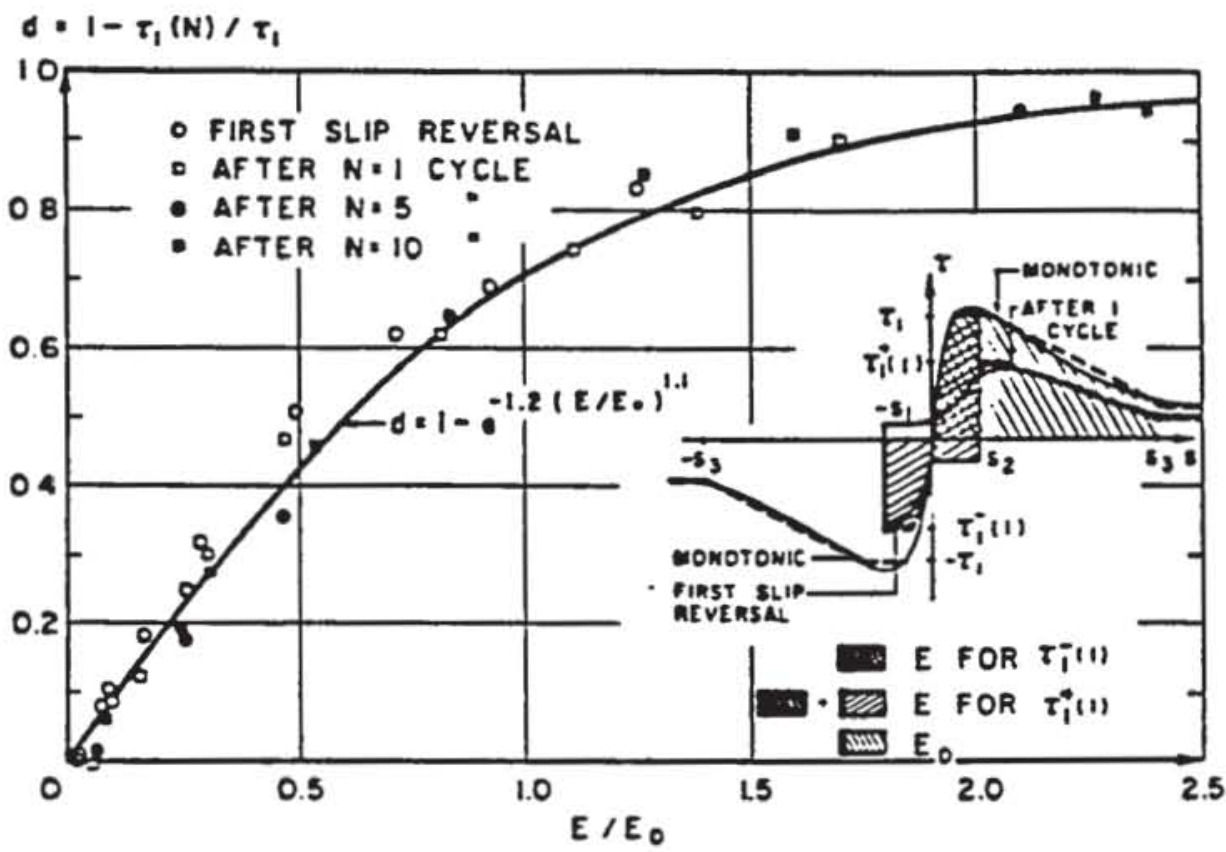

Fig.24 Damage parameter $d$ as a function of the dimensionless energy dissipation; Ciampi, Eligehausen, Bertero and Popov [21]

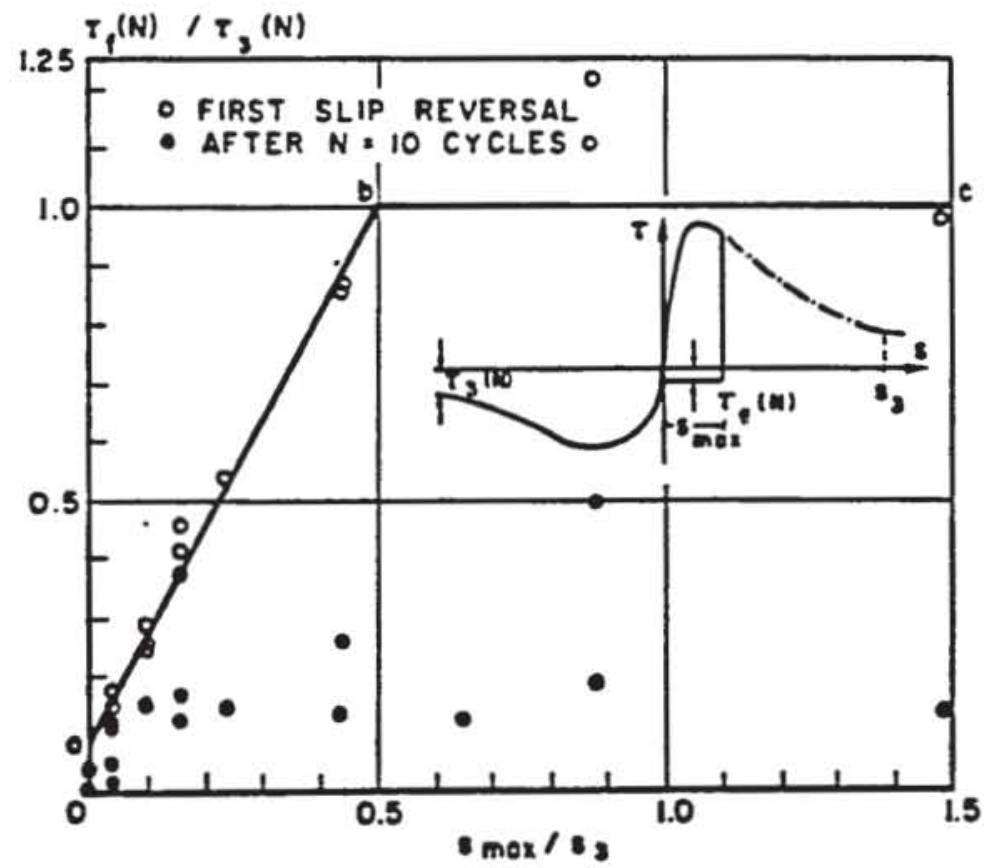

Fig.25 Relationship between the frictional bond resistance $\tau_{f}(N)$ and the corresponding ultimate frictional bond resistance $\tau_{3}(N)$; Ciampi, Eligehausen, Bertero and Popov [21) 
$s_{\max }$ or $s_{\min }$ (e.g., path $G H M$ ), the damage parameter is linearly interpolated between the values valid for the last slip reversal and for the completed cycle (point $E$ and point $P$ in this example). For more details, see Ref. [5].

It should be observed that the proposal for calulating the damage parameter as a function of the total dissipated energy is theoretically correct only in the range of the low cycle fatigue; that is, when a small number of cycles at relatively large slip values is carried out. In fact, if a high number of cycles at small slip values is performed, the energy dissipated can be relatively large, but no significant damage is produced and the reloading branch reaches the monotonic envelope again [9]. On the other hand, when limiting our attention to a small number of cycles ( $\leq 30)$, as the present study, the energy dissipated for cycles between small slip values is rather small and the calculated damage, as a consequence, insignificant.

The frictional bond resistance after first unloading ( $\tau_{f}$ in Fig. 22) depends upon the peak value of slip, $s_{\max }$, and is related to the value of the ultimate frictional bond resistance of the corresponding reduced envelope ( $\tau_{3}$ in Fig.22). The relationship found in the tests is shown in Fig.25. However, if cycling is done between fixed values of slip (e.g., between fixed $s_{\max }$ and $s_{\min }$ in Fig.22), $\tau_{f}$ is reduced more rapidly than the ultimate $\tau_{3}$ of the corresponding reduced envelope. Therefore, the analytical function, in Fig.24 is used only for the calculation of the frictional resistance for the first slip reversal. For subsequent cycles, $\tau_{f}$ (e.g., $\tau_{f}$ in Fig.22) is reduced from this initial value by multiplying it with an additional reduction factor which depends on the energy dissipated by friction alone. If unloading is done from a larger slip value than the peak slip in the previous cycle (path STU), the new frictional bond resistance $\left(\tau_{f \omega}\right)$ is linearly interpolated between two values. The first value is related to $\tau_{3}$ of the corresponding new reduced envelope using the analytical function given in Fig.25, and the second value is the $\tau_{f}$ reached in the last cycle ( $\tau_{f}$ in Fig.22). This interpolation is done in order to have a smooth transition in the values $\tau_{\mathrm{f}}$.

Note that the concept of relating damage to one scalar quantity, like the normalized dissipated energy, has provided a basis for a relatively easy generalization of the bond behaviour for random excitations. The bond model selected can easily be extended to cover bond of bars under conditions different from those reported herein, such as different bar diameter, pattern of deformation (lugs), concrete strength, degree of confinement, effect of transverse pressure, etc. This requires that the pertinent experimental data necessary for computing the different parameters, in particular the 


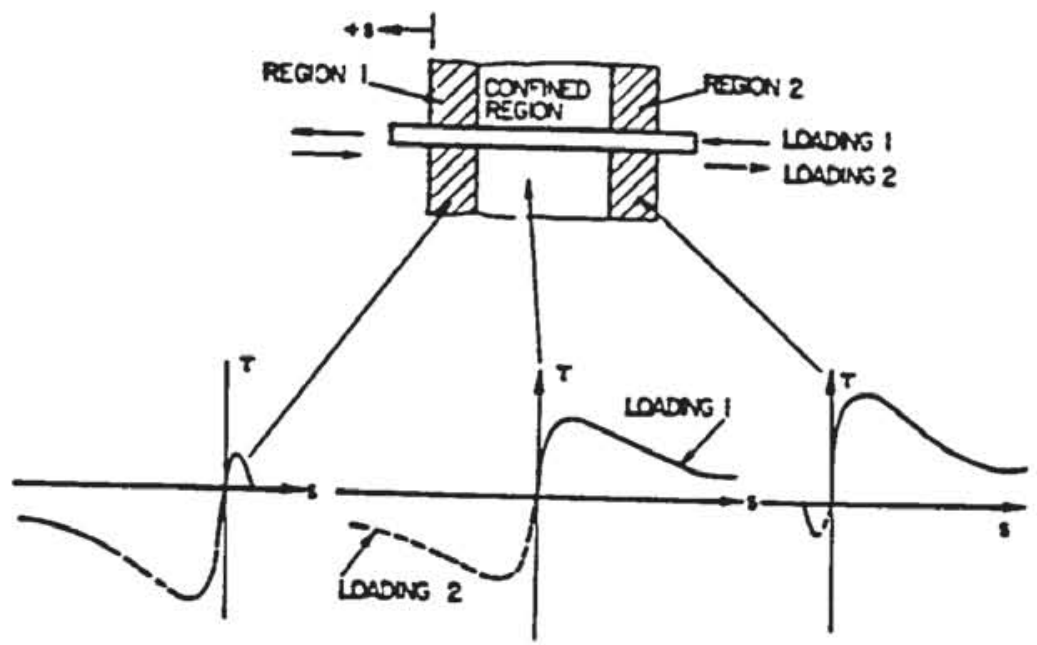

Fig.26 Different bond regions in an interior joint [25]
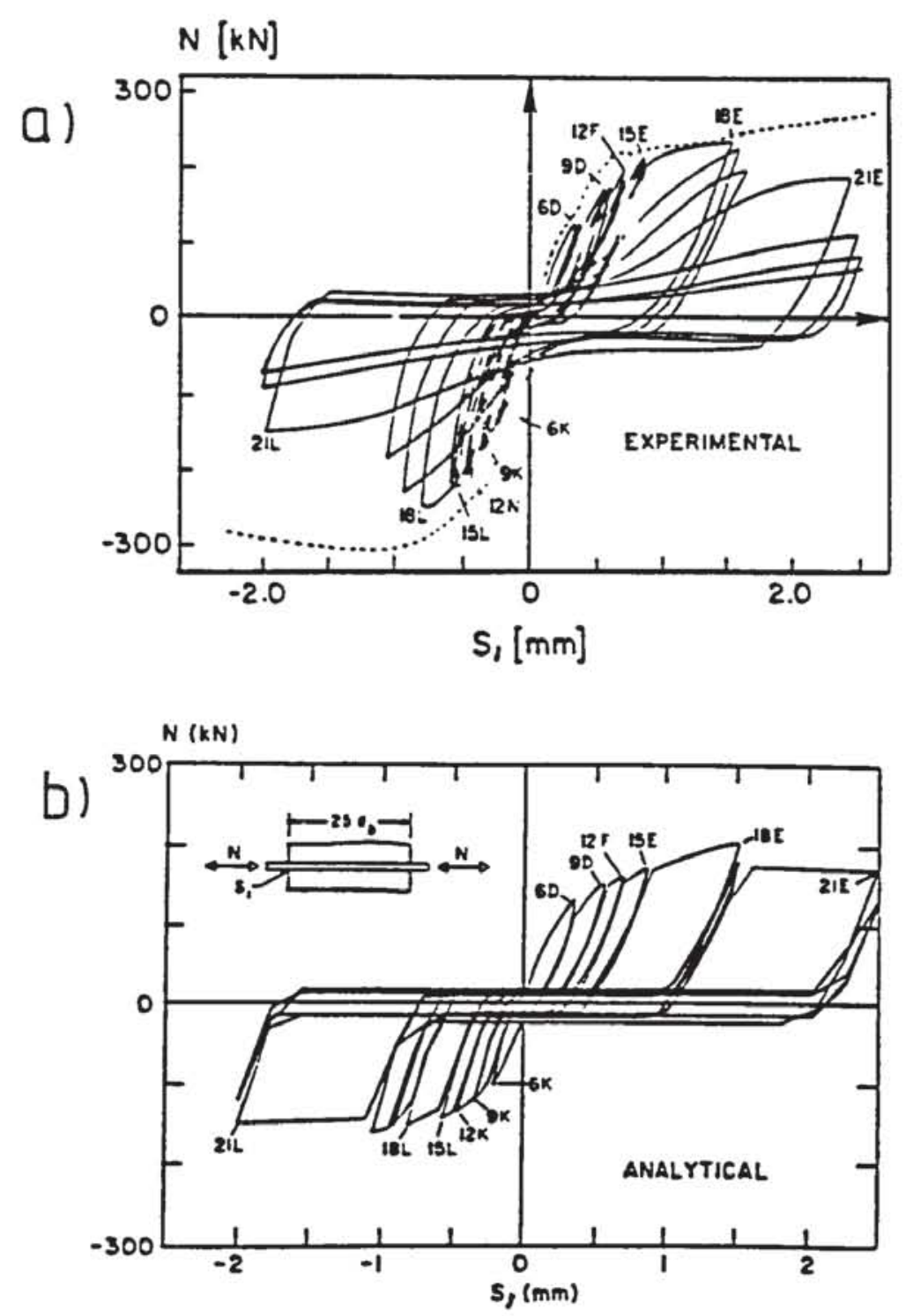

Fig.27 Comparison between experimental (a) and analytical (b) results; Ciampi, Eligehausen, Bertero and Popov [21] 
monotonic envelope, be obtained. If these are not available, the suggestions given in [5] could be used for choosing the required parameters.

The bond conditions in a joint vary along the embedment length. For an interior joint, three different regions have been identified in [25] (see Fig.26). They show differences both in the shape of the monotonic envelopes, different for positive and negative slip, and in the rate at which degradation occurs. Of course, there is a gradual variation in the behaviour proceeding from an unconfined region to the confinedone.

The possibility of extending the analytical model presented here for confined concrete to the unconfined regions, using information contained in [25], is discussed in detail in [5]. The analytical bond model is generalized as follows:

- instead of only one, two different monotonic envelopes are specified, one for positive and one for negative slip values (compare Fig.26);

- the normalizing energy, $E_{0}$, used in the computation of damage is chosen as the larger one between $E_{0}$ and $E_{0}$. These quantities define the corresponding areas under the monotonic envelopes for positive and negative slip values up to slip value $s_{3}$. To take into account different rates of damage in the two directions of loading, the pertinent dissipated energy, E, used for computing the reduced envelopes, is multiplied by an amplification factor, b, which is different for the upper and lower curve. The factors $b^{+}$and $b^{-}$are specified as input values. Similar rules for the computation of damage apply to the friction part of the curves.

More details regarding the quantification of the various parameters involved, and of their distribution along the anchorage length in an interior beam-column joint, are contained in [5] and [21]. A comparison between experimental and analytical results concerning a bar with a bond length of 25 bar diameter is presented in Fig. 27 .

\subsubsection{Model by Pochanart and Harmon [28]}

The following rules define the hysteresis rules for bond under generalized excitations (Fig.28.c).

1. Under monotonic loading, the bond-slip relationship follows the monotonic 

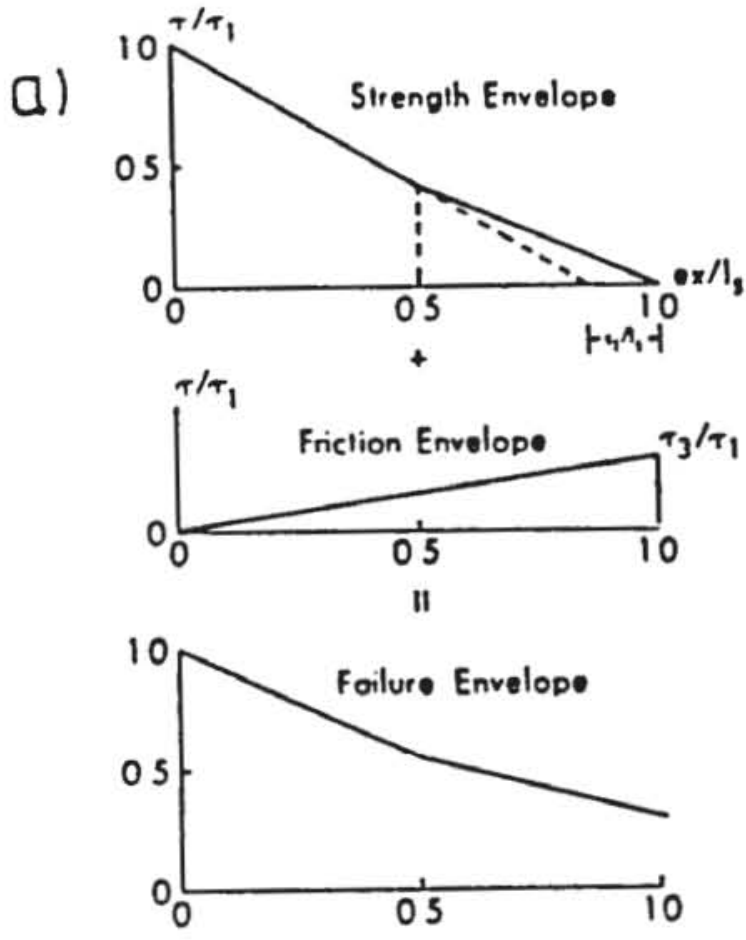

b) Bond Stress

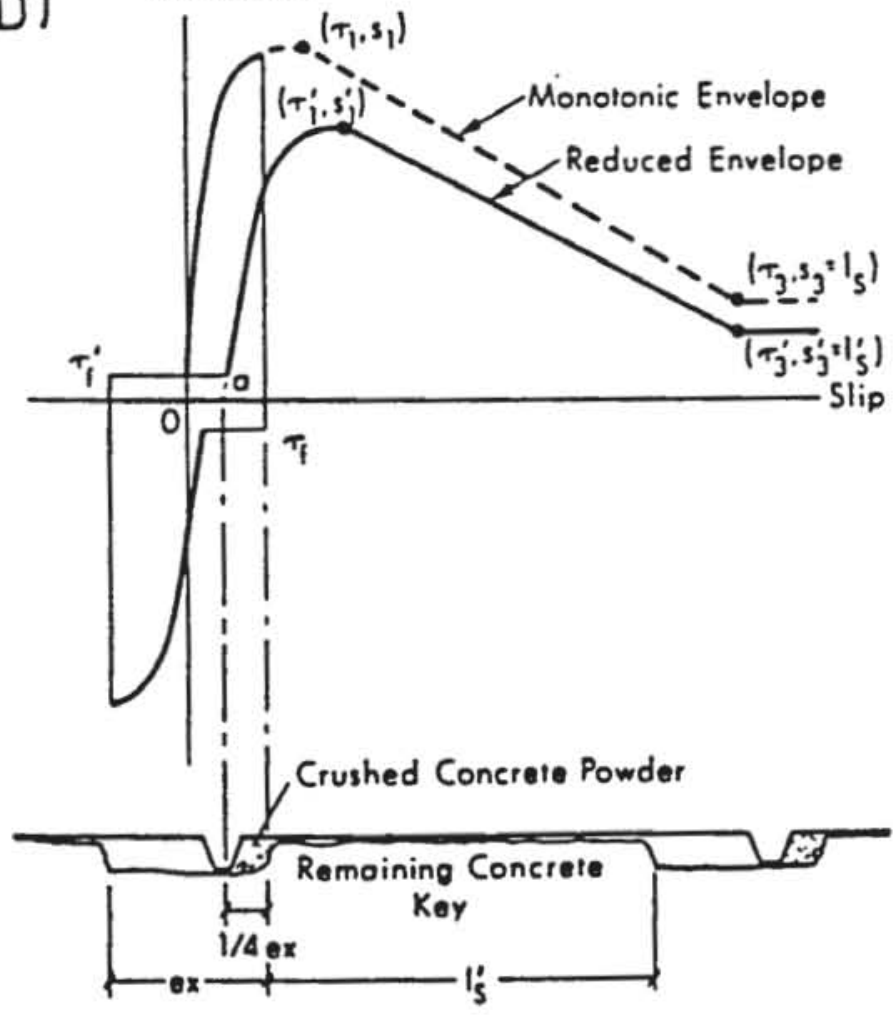

C)
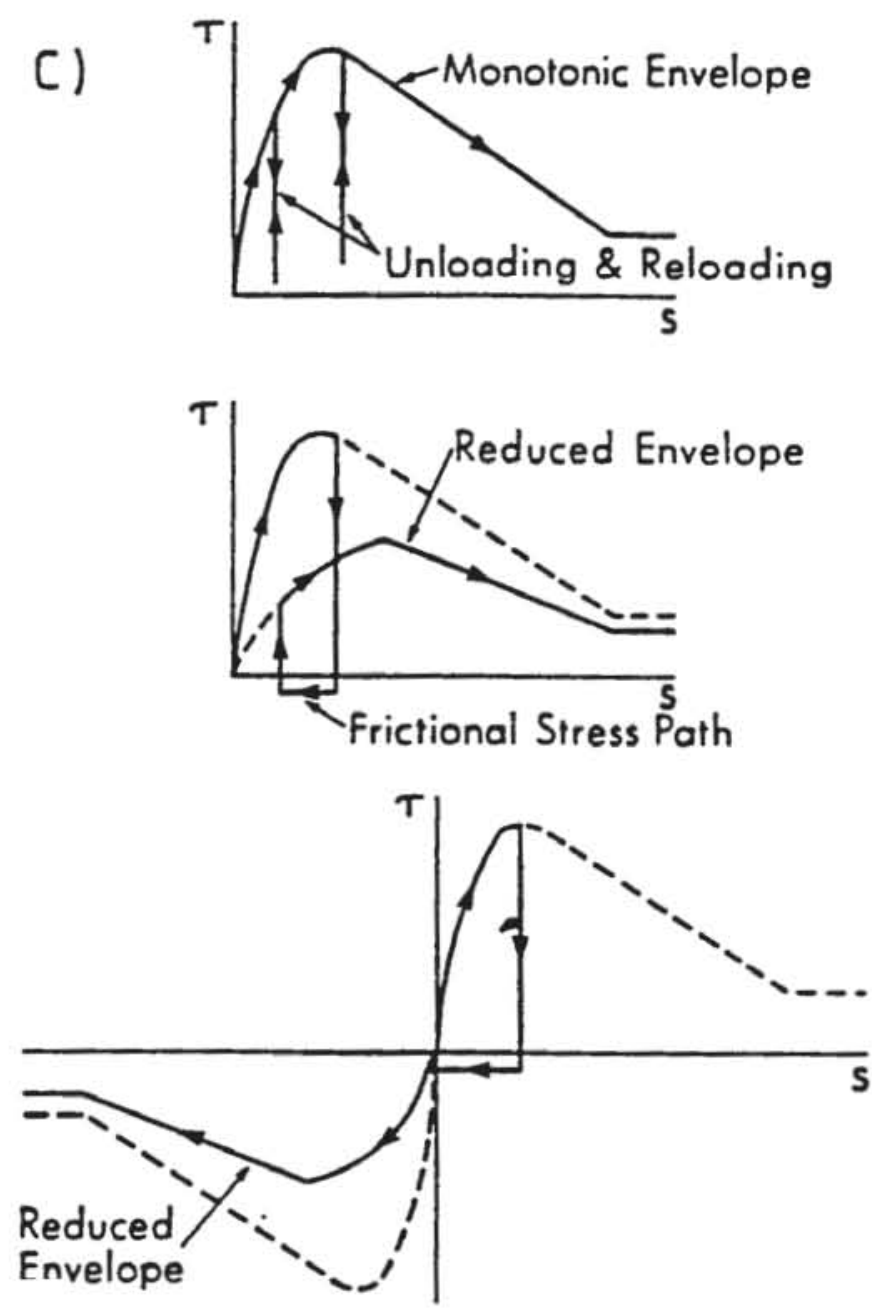

Fig.28 Bond model for generalized excitations, failure envelope (a), reduced envelope (b), and bond stress slip-law (c); Pochanart and Harmon [28] 
envelope.

2. The unloading path is very stiff (Fig.28.c).

3. As long as there is no slip to the opposite direction, reloading will be on the same path as unloading. When the stress reaches the point where the unloading took place, the bond slip relationship will still follow the previous envelope (Fig.28.c).

4. If the reversed load is higher than the developed frictional bond stress, there will be slip to the opposite direction, and the reduced envelope based on the remaining concrete key will be used as the new envelope (Fig.28.c).

5. If reloading takes place after there is slip to the opposite direction, the reloading path follows the unloading stiffness relationship until either a reduced envelope or frictional envelope is crossed.

6. If loading continues to the opposite direction, the loading path will follow the frictional stress path until it crosses the new envelope and then will follow the new envelope.

The reduced monotonic envelope is shown in Fig.28.b. After cyclic loading, during which the maximum total excursion was ex, the monotonic envelope is reduced as shown in the figure and is defined by $\tau^{\prime}{ }_{1}$ and $s^{\prime}{ }_{1}$, the new peak bond stress and corresponding slip value; by $\tau_{3}^{\prime}$, the new residual frictional stress value; by $s_{3}^{\prime}=$ $\mathrm{l}_{3}$, the undamaged length of the concrete key; and by $\tau_{f}^{\prime}$, the current value of the developed frictional stress. Also needed is an offset value that tells where the strength component of the reduced envelope begins. In Fig. 30.b, this offset value is set to $1 / 4$ of ex.

$\tau^{\prime}{ }_{1}$ is composed of two components: the strength component and the friction component. The strength component is obtained from Fig.28.a given the total excursion. The friction component is determined from the friction model shown in Fig.28.a by keeping track of the developed friction lost during load cycling. The slip $s^{\prime}{ }_{1}$ corresponding to $\tau^{\prime},{ }_{1}$ can be obtained easily since experimental results show that $s^{\prime}$, minus the positive excursion is a constant percentage of $1^{\prime}{ }_{s}$, the undamaged length of the concrete key which equals $1_{s}$-ex. $\tau^{\prime}{ }_{3}$ and $\tau_{f}^{\prime}$ are obtained by keeping track of the developed friction and the loss of friction due to load cycling.

The deterioratoin of the frictional bond stress can be determined by assuming that the frictional bond stress reduces by about 18 percent from the frictional bond stress of the previous cycle, assuming no new frictional bond resistance is developed 
during the cycle, that is, that the test is performed under slip control. The deterioration of the bond strength is obtained given the maximum total excursion and the strength model of Fig.28.a. These two rules define the damage law for bond.

The model appears to be able to predict a wide range of bond-slip behaviour, including the results of both slip controlled and load controlled tests from 100 to 40000 cycles (the limits were given by the authors). The behaviour under cyclic loading can be predicted reasonably well by repeated applications of a simple damage law applied to the reduced envelop. The shifting of the ordinate axis of the bond-slip co-ordinate system is a visual interpretation of the slip increase without an increase of bond stress during the frictional bond behaviour, however the value of shifting and the shape of the ascending branch may need more specific studies. The basic difference of the models proposed by Ciampi, Eligehausen, Botero, Popov and by Pochanart, Harmon is the definition of the bond damage during cycling.

\subsubsection{An application by Filippou [26]}

Filippou recently [26] presented a model describing the hysteretic behaviour of a single reinforcing bar anchored in an interior beam-column joint. An extension of the model to exterior joints is relatively straightforward. The model focuses attention on the stress transfer between reinforcing bars and surrounding concrete through bond. The portion of single reinforcing bar between the beam-column interfaces of an interior joint is depicted in Fig.29.a The model proposed is as follows:

(1) The bar is subdivided by points A, B, C, D and M into four basic segment Points $\mathrm{A}$ and $\mathrm{D}$ are located at the ends of the bar. Point $\mathrm{M}$ is located at the bar midpoint, while points $\mathrm{B}$ and $\mathrm{C}$ mark the transition between the confined and unconfined concrete region at the end of pull out cone. Additional points $\mathrm{E}$ and $\mathrm{F}$ can be inserted in order to increase the numerical accuracy of integrations.

(2) The bond stress is always zero at the ends of the bar (points A and D in Fig.29.a). As the magnitude of bar pull-out increases, bond is gradualy destroyed at the ends of the bar. This region of zero bond stress spreads into the joint with increasing magnitude of bar pullout (segment A- $A_{\circ}$ in Fig.29). At the bar end that is pulled out a linear bond stress distribution is assumed between point $A_{\circ}$ and point $B$ located at the transition between the confined and the unconfined 
a)
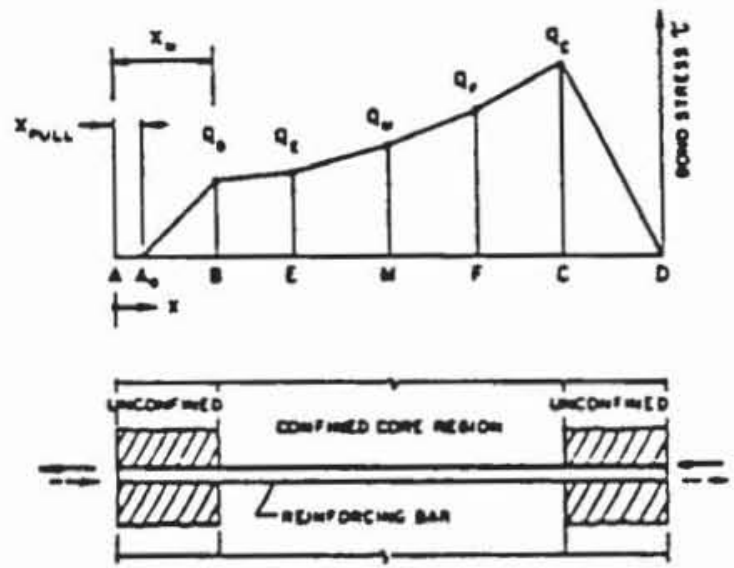

b)

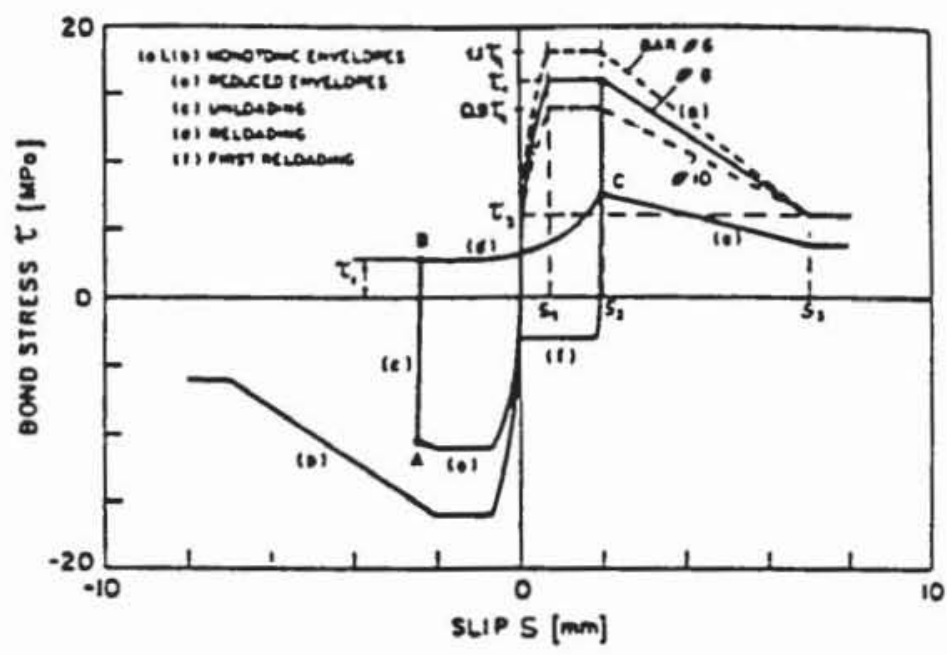

Fig.29 Assumed bond stress distribution (a) and hysteratic bond-slip relationship (b); Filippou [26], [27]

a)
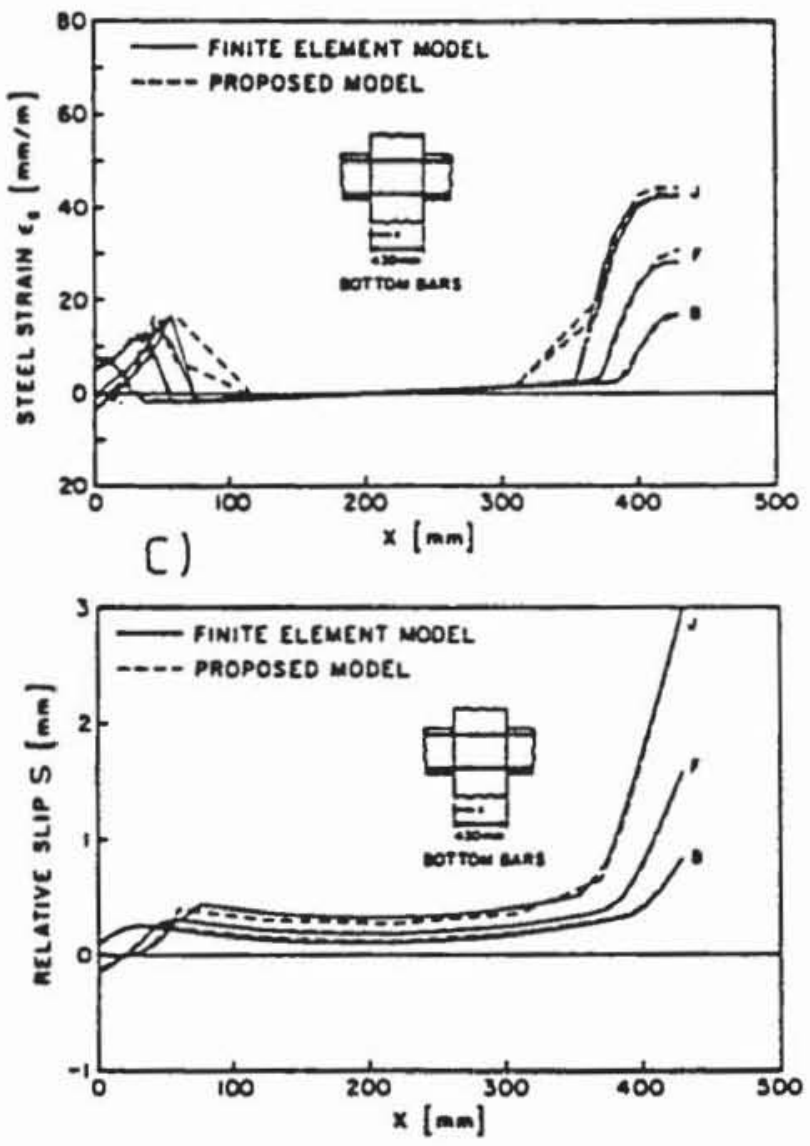

b)
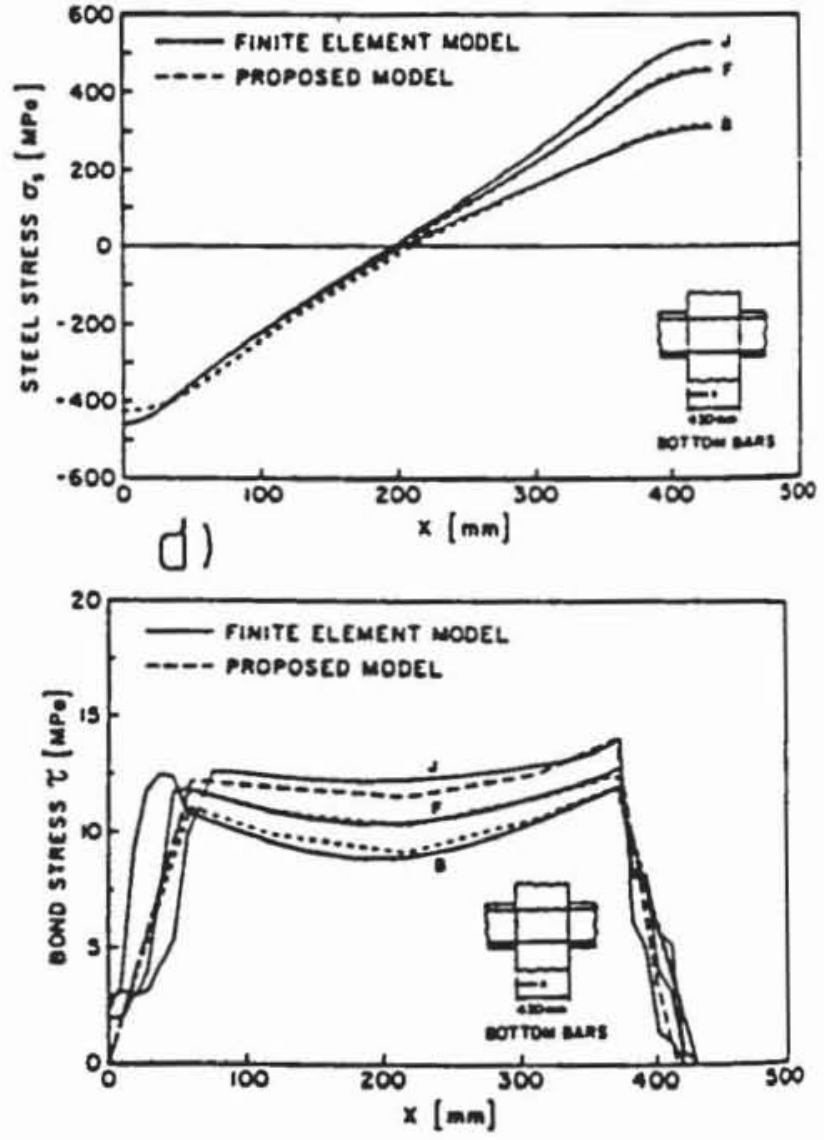

Fig.30 Distribution of seel strain (a), steel stress (b), slip (c) and bond stress in a frame joint with increasing magnitude of end slip; Filippou [26] 
concrete region at the end of the pull-out cone. At the bar end that is pushed in, a linear bond stress distribution is assumed between the end of the bar, point $D$, and point $\mathrm{C}$ which is located at the transition between the confined and the unconfined concrete region.

(3) The bond stress distribution in the confined concrete region between points B and C is assumed piecewise linear and is established iteratively satisfying the equilibrium and compatibility conditions using the bond model shown in Fig.29.b.

A typical hysteretic bond stress-slip curve concerned is illustrated in Fig.29.b. This curve describes the stress transfer between reinforcing steel and confined concrete as a function of the relative slip between the reinforcing bar and the surrounding concrete. The effect of bar diameter on the monotonic envelope curve is also shown in Fig.29.b. During each half cycle following the first unloading, the monotonic envelope is reduced based on the total energy dissipated during previous half cycles. This establishes the reduced envelope [curve (e) in Fig.29.b.]. The applied bond stress-slip curve is practically the same as proposed by Ciampi, Eligehausen, Bertero and Popov [21] (Fig.22) with a slight modification in the ascending branch during cycling taking a non-linear increase of band stress after the fictional branch instead of an abrupt change reaching the previous maximum slip. Experimental and analytical

The model is capable of predicting the behaviour of bars in well confined interior or exterior joints under cyclic excitation. Experimental and analytical results are presented in Fig.30 for comparision.

Note that the solution scheme proposed in this study bypasses the problem of having to define a bond stress-slip relation for portions of the reinforcing bar embedded in unconfined concrete. The bond stress-slip relation is only satisfied at points B, M and C in Fig.29.a which lie in the confined region of the joint. The assumed linear bond distribution between points $\mathrm{A}$ and $\mathrm{B}$ at one bar end and points $\mathrm{C}$ and $\mathrm{D}$ at the other end removes the need for defining a bond stress-slip relation in the unconfined concrete regions at the ends of the bar (segments A-B and C-D in Fig.29.a). This is a great advantage of the proposed model, since the hysteretic bond stress-slip relation in unconfined concrete regions is not well established. 


\subsection{Conclusions}

Cycles with reversed loading produce degradation of bond strength and bond stiffness that is more severe than for the same number of load cycles with unidirectional loading. Degradation primaraly depends on the peak slip in either direction reached previously. Other significant parameters are rib pattern, concrete strength, confining effects, number of load cycles and peak value of slip between which the bar is cyclically loaded. Under otherwise constant conditions, the largest deterioration will occur for full reversals of slip. The accumulation of bond damage is supposed to be caused by the progressive growth of microcracks and concrete micro-crushing in front of the protruding lugs.

Although the models simplify the real behaviour, they intend to take into account parameters appear to control the behaviour observed in the experiments being: deterioration of bond strength, deterioration of related slip, increase of slip under load-controlled reversals, decrease of bond stress under slip-controlled reversals, deterioration of frictional bond stress and deterioration of residual bond strength.

Using the described rather sophisticated bond models, the behaviour of bars embedded in concrete under cyclic excitations can be predicted with sufficient accuracy for practical purposes.

\section{REFERENCES}

[1] Goto, Y., "Cracks Formed in Concrete Around Deformed Tension Bars." ACI Journal, Vol. 62, No. 1, January 1965, pp. 71-93.

[2] Giuriani, E., "Experimental Investigation on the Bond-Slip Law of Deformed Bars in Concrete", LABSE Colloquium Delft 1981, IABSE, Zurich 1981, pp. 121-142.

[3] Rehm, G., "Über die Grundlagen des Verbundes zwischen Stahl und Beton", Deutscher Ausschuss für Stahlbeton, Heft 138, 1961.

[4] CEB - Comite Euro-International du Béton, "State of the Art Report: Bond Action and Bond Behaviour of Reinforcement," Bulletin d'Information No. 151, Paris, December 1981.

[5] Eligehausen, R., Popov, E.P. and Bertero, V.V., "Local Bond Stress-Slip Relationships of Deformed Bars Under Generalized Excitations", Report No. UCB/EERC 83-23, Earthquake Engineering Research Center, University of California, Berkeley, California, Oct., 1983.

[6] CEB - Comité Euro-International du Béton, "CEB - FIP Model Code 1990 Frist Draft", 
Bulletin d'Information No. 195, Paris, Sept. 1990

[7] Bresler, B. and Bertero V., "Behaviour of Reinforced Concrete Under Repeated Load", Journal of the Structural Division, ASCE, Vol. 94, ST6 June 1968, pp. 1567-1590.

[8] Edwards, A.D. and Yannopoulos, P.J., "Local Bond Stress-Slip Relationship Under Repeated Loading", Magazine of Conctete Research Vol. 30, No. 103, June 1978, pp. 62-72.

[9] Rehm, G. and Eligehausen, R., "Bond of Ribbed Bars under High-Cycle Repeated Loads", $A C I$ Journal, Vol. 76, No. 2, Feb. 1979.

[10] Rehm, G. and Eligehausen, R., "Bond of Ribbed Bars under Repeated Loads", Report 291, German Institute for Reinforced Concrete, Berlin 1977 (in German).

[11] Balázs, G.L., "Bond Behavior Under Repeated Loads", Studie e Ricerche - Corso Flli. Pesenti, Politecnico di Milano, Vol. 8, 1986, pp. 395-430.

[12] Balázs, G.L., "Bond Behaviour Under Repeated Load", CEB Bulletin d'Information No. 195, Mai 1988 Treviso, pp. 197-202.

[13] Balázs, G.L., "Fatigue of Bond", paper accepted for publication by ACI Materials Journal

[14] Shah, S.P. and Chung, L., "Effect of Cyclic Loading Rate on Response of Model Beam-Column Joints and Anchorage Bond", Proceedings of the 3rd U.S. Nat. Conf. Earhquake Eng., EERI, San Francisco, 1986.

[15] Rilem, "Dynamic Behaviour of Concrete Structures", Report of the RILEM 65 MDB Committee, G.P. Tilly (ed.), Elsevier, Amsterdam, 1986.

[16] Tassios, T.P., "Properties of Bond Between Concrete and Steel Under Load Cycles Idealizing Seismic Actions", AICAP-CEB Symposium, Structural Concrete Under Seismic Actions, Comité Euro-International Du Béton, Bulletin d'Information, No. 131, Vol. 1, Rome, Italy, 1979.

[17] CEB - Comité Euro-International du Béton, "Response of R.C. Critical Regions under Large Amplitude Reversed Actions", Bulletin d'Information No. 161, Prague, Oct. 1983.

[18] ACI Committee 408, "Bond under Cyclic Loading", State of the An Report

[19] Morita, S. and Kaku, T., "Local Bond Stress-Slip Relationship Under Repeated Loading", LABSE Symposium, Resistance and Ultimate Deformability of Structures Acted on by Well Defined Repeated Loads, Lisboa, 1973, pp. 221-227.

[20] Eligehausen, R., Bertero, V.V. and Popov, E.P., "Hysteretic Behavior of Reinforcing Deformed Hooked Bars in R/C Joints", Vol. 4, Proceedings of the Seventh European Conference on Earthquake Engineering, Athens, September 1982, pp. 171-178.

[21] Ciampi, V., Eligehausen, R., Bertero, V.V. and Popov, E.P., "Analytical Model for Concrete Anchorages of Reinforcing Bars Under Generalized Excitations", Report No. EERC 82-83, Earthquake Engineering Research Center, University of California, Berkeley, Califomia, Dec., 1982.

[22] Hawkins, N.M., Lin, I.J. and Jeang, F.L., "Local Bond Strength of Concrete for Cyclic 
Reversed Loadings", Bond in Concrete (P. Bartos, ed.), Applied Science Publishers Lid., 1982, pp. 151-161.

[23] Plaines, P., Tassios, T., and Vintzleou, E., "Bond Relaxation and Bond-Slip Creep under Monotonic and Cyclic Actions", in Bond in Concrete (P. Bartos, ed.), Applied

Science Publishers Lid., 1982, pp. 193-205

[24] Balázs, G.L., "Bond Softening under Reversed Load Cycles", Studi e Ricerche - Corso Flli. Pesenti, Politecnico di Milano, Vol. 11, 1989, pp. 503-524

[25] Viwathanatepa, S., Popov, E.P. and Bertero, V.V., "Effects of Generalized Loadings on Bond of Reinforcing Bars Embedded in Confined Concrete Blocks", Earthquake Engineering Research Center, Report No. UCB/EERC-79/22, August 1979.

[26] Filippou, F.C., "A Simple Model For Reinforcing Bar Anchorages Under Cyclic Excitations", Journal of Structural Engineering, ASCE, Vol. 112, No. 7, July 1986.

[27] Filippou, F.C., Popov, E.P., Bertero, V.V. and "Effects of Bond Deterioration on Hysteretic Behavior of Reinforced Concrete Joints", Report No. UCB/EERC 83-19, Earthquake Engineering Research Center, University of California, Berkeley, California, Aug. 1983.

[28] Pochanart, S. and Harmon, T., "Bond-Slip Model for Generalized Excitation Including Fatigue", ACl Materials Journal, Sept-Oct 1989, pp. 465-476.

[29] Fehling, E., "Zur Energiedissipation und Steifigkeit von Stahlbetonbauteilen unter besonderer Berücksichtigung von Rißbildung und verschieblichem Verbund", Dissertation, Darmstadt, 1990

[30] Lieberum, K.H.," Das Tragverhalten von Beton bei extramer Teilflächenbelastung", Dissertation, TH Darmstadt 1987, D 17

[31] Rohling, A., Rostasy, F.S.: Zum Einfluß des Verbundkriechens auf die Rißbreitenentwicklung sowie auf die Mitwirkung des Betons aus Zug zwischen den Rissen. Institut für Baustoffe, Massivbau und Brandschutz, Technische Universitāt Braunschweig, Deutsche Forschungsgemeinschaft Bonn, Fachseminar 19. und 20. Mai 1988, p. $133 \mathrm{ff}$. 